\title{
Valsartan combination therapy in the management of hypertension - patient perspectives and clinical utility
}

This article was published in the following Dove Press journal:

Integrated Blood Pressure Control

23 October 2009

Number of times this article has been viewed

\author{
David T Nash' \\ Michael S McNamara ${ }^{2}$ \\ 'Syracuse Preventive Cardiology, \\ Syracuse, New York, USA; ${ }^{2}$ Oxford \\ PharmaGenesis Inc., Newtown, \\ Pennsylvania, USA
}

Correspondence: David T Nash

Clinical Professor of Medicine, Syracuse Preventive Cardiology, 600 East Genesee Street, Syracuse, NY I3202, USA

Tel + | 3|5-475-992|

Fax + | 315-472-7/03

Email davidtnash@aol.com

\begin{abstract}
The morbidity and mortality benefits of lowering blood pressure (BP) in hypertensive patients are well established, with most individuals requiring multiple agents to achieve BP control. Considering the important role of the renin-angiotensin-aldosterone system (RAAS) in the pathophysiology of hypertension, a key component of combination therapy should include a RAAS inhibitor. Angiotensin receptor blockers (ARBs) lower BP, reduce cardiovascular risk, provide organ protection, and are among the best tolerated class of antihypertensive therapy. In this article, we discuss two ARB combinations (valsartan/hydrochlorothiazide [HCTZ] and amlodipine/valsartan), both of which are indicated for the treatment of hypertension in patients not adequately controlled on monotherapy and as initial therapy in patients likely to need multiple drugs to achieve BP goals. Randomized, double-blind studies that have assessed the antihypertensive efficacy and safety of these combinations in the first-line treatment of hypertensive patients are reviewed. Both valsartan/HCTZ and amlodipine/valsartan effectively lower BP and are well tolerated in a broad range of patients with hypertension, including difficult-to-treat populations such as those with severe BP elevations, prediabetes and diabetes, patients with the cardiometabolic syndrome, and individuals who are obese, elderly, or black. Also discussed herein are patient-focused perspectives related to the use of valsartan/HCTZ and amlodipine/valsartan, and the rationale for use of single-pill combinations as one approach to enhance patient compliance with antihypertensive therapy.
\end{abstract}

Keywords: amlodipine, combination therapy, hydrochlorothiazide, hypertension, valsartan

\section{Introduction}

Almost one in three adults in the United States has hypertension, ${ }^{1}$ and it remains a significant risk factor for cardiovascular disease. ${ }^{1,2}$ Hypertension is associated with substantial morbidity and mortality. ${ }^{3}$ Target organs that may be affected include the heart, brain, vasculature, kidneys, and eyes. Persistent blood pressure (BP) elevation may result in an acceleration of atherosclerosis, coronary heart disease, heart failure, and renal failure. ${ }^{3}$ Although not fully established, there are also numerous reports of a possible relationship between hypertension and an increased risk of cognitive decline and vascular dementia. ${ }^{4}$ Hypertension is perhaps the most important individual and societal health burden in terms of costs and loss of quality-adjusted life years. ${ }^{5}$ Although in recent years the proportion of hypertensive patients receiving treatment and the rate of BP control have increased, control rates still remain low. ${ }^{6}$ Results of the National Health and Nutrition Examination Survey (2003-2004) indicate that only approximately $37 \%$ of all hypertensive patients are controlled (systolic blood pressure $[\mathrm{SBP}] /$ diastolic blood pressure $[\mathrm{DBP}]<140 / 90 \mathrm{mmHg}$ if nondiabetic or $<130 / 80$ 
$\mathrm{mmHg}$ if diabetic). Even among treated hypertensive patients, control rates are only about $57 \%$ and substantially lower among diabetics (38\%). ${ }^{6}$ The management of hypertension is complicated by the fact that most of this population has additional comorbidities/cardiometabolic risk factors. ${ }^{7-11}$

It is recommended that lifestyle interventions (smoking cessation, weight loss, exercise, reductions in alcohol, salt, and fat intake, and increased fruit/vegetable consumption) be instituted whenever appropriate in all hypertensive patients. ${ }^{2,12}$ Unfortunately, long-term compliance with such measures is low, ${ }^{2}$ although well-designed community-based efforts were shown to reduce BP, to improve lifestyle choices and health habits, and to reduce levels of cardiovascular risk in the population. ${ }^{13,14}$ In addition to lifestyle interventions, most hypertensive patients will require antihypertensive therapy with a combination of agents to reach BP goals. ${ }^{2,15}$ For example, in ASCOT-BPLA, nearly $90 \%$ of participants were on multiple antihypertensive agents by the end of the trial. ${ }^{16}$ Antihypertensive drugs of different classes can be combined if: they have different and complementary mechanisms of action; the efficacy of the combination is greater than that of either component; and the complementary mechanisms of action lead to a favorable tolerability profile. The advantages of this approach are that: low doses of the individual components can be used; the process of searching for effective monotherapies in patients at high risk can be avoided; and the BP target level can be reached more quickly. The need for combination therapy is particularly relevant for high-risk hypertensive patients such as those with diabetes or chronic kidney disease. A coexistent diagnosis of hypertension and diabetes increases the risk of adverse cardiovascular and renal outcomes, and the increased risk extends down to SBP/DBP levels as low as $127 / 83 \mathrm{mmHg} .{ }^{17}$

Results of numerous landmark clinical trials such as the VA Cooperative, ${ }^{18,19}$ HDFP, ${ }^{20}$ SHEP, ${ }^{21}$ Syst-Eur, ${ }^{22}$ CONVINCE,${ }^{23}$ INVEST,${ }^{24}$ SCOPE,${ }^{25}$ CAMELOT, ${ }^{26}$ VALUE, ${ }^{27}$ ASCOT-BPLA, ${ }^{16}$ and ACCOMPLISH ${ }^{28}$ have demonstrated that several classes of antihypertensive agents, administered alone or most often in combination, can reduce BP and improve cardiovascular outcomes. Some evidence suggests that lowering elevated BP with antihypertensive therapy may also have a protective effect against vascular dementia and cognitive decline. ${ }^{4,29}$ Although a lack of benefit in this regard has also been reported, there is no empirical evidence to suggest that treatment of hypertension has negative effects on brain function, including in the very elderly. ${ }^{30,31}$ Antihypertensive regimens that suppress the renin-angiotensin-aldosterone system (RAAS) are of particular interest given the important role of the RAAS in cardiovascular and renal disorders and the ability of RAAS inhibitors to not only lower BP and reduce cardiovascular risk but to also provide organ protection. ${ }^{32,33}$ Angiotensin receptor blockers (ARBs) have BP-lowering ${ }^{34}$ and cardiorenal protective effects ${ }^{35-39}$ that are similar to those of angiotensin-converting enzyme (ACE) inhibitors, but with better tolerability. ${ }^{34}$ When ARBs are administered as part of combination therapy, an optimal approach is to include a diuretic or calcium channel blocker (CCB). ${ }^{40}$

In this review, we discuss the key studies that have assessed the antihypertensive effects of valsartan, one of the most extensively studied ARBs, when used in combination with the diuretic hydrochlorothiazide (HCTZ) or the CCB amlodipine in the first-line treatment of hypertension and its associated comorbidities. The studies described were not designed to assess clinical outcomes or effects on cognitive function. To date, studies involving amlodipine/valsartan have focused on BP control; outcomes studies are not available. In addition, no outcomes studies are available on the first-line use of valsartan/HCTZ, although a study in high-risk hypertensive patients in which HCTZ was a possible add-on therapy to valsartan demonstrated the benefits of this treatment on cardiovascular morbidity and mortality. ${ }^{27}$ Valsartan therapy has also shown benefits on hard endpoints in nonhypertensive populations including patients with chronic heart failure ${ }^{41}$ and postmyocardial infarction. ${ }^{42}$ The latter part of this article presents patient-focused perspectives related to the use of valsartan/HCTZ and amlodipine/valsartan, along with a discussion of compliance in the treatment of hypertension and the rationale for the use of single-pill combinations.

\section{Valsartan combination therapies Valsartan/hydrochlorothiazide (HCTZ)}

The combination of valsartan/HCTZ is indicated in patients whose BP is not adequately controlled on monotherapy, and it is now also approved for use as first-line treatment in patients likely to need multiple drugs to achieve their BP goals. All studies discussed employed a randomized, double-blind design and, in all cases, study medication was administered once daily. A section on safety and tolerability follows the discussion of efficacy.

\section{Mild to moderate hypertension}

Phase III studies

Two 8-week, placebo-controlled studies compared the antihypertensive efficacy of valsartan/ HCTZ versus monotherapy. In one study, 871 patients with mild to moderate hypertension, defined as DBP 
95-115 mmHg, were evaluated. ${ }^{43}$ Patients received valsartan/ HCTZ 80/12.5 mg, 80/25 mg, 160/12.5 mg, or 160/25 mg; valsartan $80 \mathrm{mg}$ or $160 \mathrm{mg}$; HCTZ $12.5 \mathrm{mg}$ or $25 \mathrm{mg}$; or placebo for 8 weeks. The primary endpoint was change in mean seated DBP (MSDBP) from baseline. Placebo-subtracted changes in mean seated SBP (MSSBP)/MSDBP from baseline to 8 weeks were $-14.6 /-7.7 \mathrm{mmHg},-19.2 /-11.2 \mathrm{mmHg}$, $-15.8 /-9.4 \mathrm{mmHg}$, and $-20.5 /-11.2 \mathrm{mmHg}$ with valsartan/ HCTZ 80/12.5 mg, 80/25 mg, 160/12.5 mg, and 160/25 mg, respectively; $-6.9 /-4.5 \mathrm{mmHg}$ and $-10.2 /-5.3 \mathrm{mmHg}$ with valsartan $80 \mathrm{mg}$ and $160 \mathrm{mg}$, respectively; and $-5.4 /-3.0 \mathrm{mmHg}$ and $-10.8 /-5.2 \mathrm{mmHg}$ with HCTZ $12.5 \mathrm{mg}$ and $25 \mathrm{mg}$, respectively. Combination therapy provided significantly greater antihypertensive efficacy relative to placebo and the corresponding monotherapies $(P<0.05)$.

The second placebo-controlled study investigated the antihypertensive efficacy of valsartan and HCTZ alone and in combination at doses up to $320 / 25 \mathrm{mg}$ in 1346 patients with $\mathrm{DBP} \geq 95 \mathrm{mmHg}$ and $<110 \mathrm{mmHg}$. ${ }^{44}$ Patients received valsartan/HCTZ 160/12.5 mg, 320/12.5 mg, or $320 / 25 \mathrm{mg}$; valsartan $160 \mathrm{mg}$ or $320 \mathrm{mg}$; HCTZ $12.5 \mathrm{mg}$ or $25 \mathrm{mg}$; or placebo for 8 weeks. The primary endpoint was change in MSDBP from baseline. Changes in MSSBP/ MSDBP from baseline to 8 weeks were $-20.3 /-15.2 \mathrm{mmHg}$, $-21.7 /-15.0 \mathrm{mmHg}$, and $-24.7 /-16.6 \mathrm{mmHg}$ with valsartan/ HCTZ 160/12.5 mg, 320/12.5 mg, and 320/25 mg, respectively; $-14.5 /-11.7 \mathrm{mmHg}$ and $-13.7 /-11.3 \mathrm{mmHg}$ with valsartan $160 \mathrm{mg}$ and $320 \mathrm{mg}$, respectively; $-11.1 /-9.0 \mathrm{mmHg}$ and $-14.5 /-10.8 \mathrm{mmHg}$ with HCTZ $12.5 \mathrm{mg}$ and $25 \mathrm{mg}$, respectively; and $-5.9 /-7.0 \mathrm{mmHg}$ with placebo. Responder rates $(\mathrm{MSDBP}<90 \mathrm{mmHg}$ or $\geq 10 \mathrm{mmHg}$ reduction from baseline) and BP control rates (MSSBP/MSDBP $<140 / 90 \mathrm{mmHg}$ ) at endpoint are shown in Figure 1. For all efficacy parameters, combination therapy provided significantly greater antihypertensive efficacy relative to placebo and the corresponding monotherapies $(P<0.05)$.

\section{Phase IV studies}

The VELOCITY study assessed the BP reduction when initiating treatment with valsartan/HCTZ compared with initiating treatment with low-dose, conventional valsartan monotherapy $(80 \mathrm{mg}$ ) or standard-dose valsartan monotherapy $(160 \mathrm{mg})$ in 648 patients with mild to moderate hypertension (SBP/DBP 150-179/90-109 mmHg), including

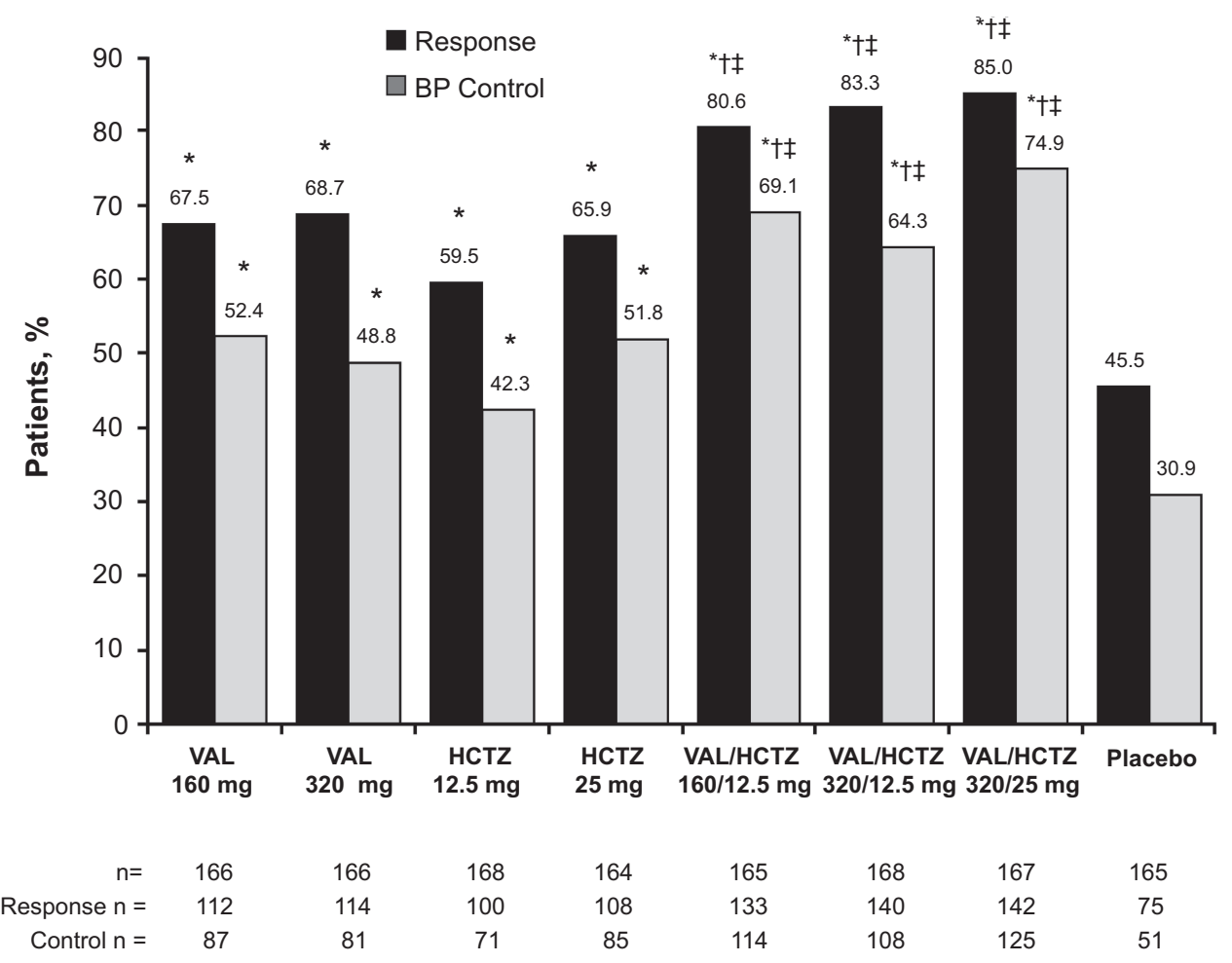

Figure I Responder rates (mean seated diastolic blood pressure [MSDBP] $<90 \mathrm{mmHg}$ or $\geq 10 \mathrm{mmHg}$ reduction from baseline) and blood pressure control rates (mean seated systolic blood pressure [MSSBP]/MSDBP $<140 / 90 \mathrm{mmHg}$ ) after 8 weeks of treatment in patients with mild to moderate hypertension.

$* P<0.05$ vs placebo; ${ }^{P} P<0.05$ vs respective HCTZ component; ${ }^{P} P<0.05$ vs respective valsartan component. Reprinted from Pool JL, Glazer R, Weinberger M, Alvarado R, Huang J, Graff A. Comparison of valsartan/hydrochlorothiazide combination therapy at doses up to 320/25 mg versus monotherapy: a double-blind, placebo-controlled study followed by long-term combination therapy in hypertensive adults. Clin Ther. 2007;29(I):6I-73.44 Copyright @ 2007, with permission from Excerpta Medica, Inc. Abbreviations: BP, blood pressure; HCTZ, hydrochlorothiazide; VAL, valsartan. 
patients with diabetes and metabolic syndrome. ${ }^{45}$ Patients received valsartan/HCTZ 160/12.5 mg, valsartan $80 \mathrm{mg}$, or valsartan $160 \mathrm{mg}$ for 6 weeks. Patients were up-titrated after 2 and 4 weeks to the next dosage level (maximum for valsartan/HCTZ: 160/25 mg) only if MSSBP/MSDBP remained $>140 / 90 \mathrm{mmHg}$. The primary endpoint was change in MSSBP from baseline to 2, 4, and 6 weeks. The level of BP reduction achieved in patients who began treatment with valsartan monotherapy (conventional step therapy) never caught up to the level achieved in patients who started with valsartan/HCTZ. Changes in MSSBP/MSDBP from baseline to 6 weeks were $-27.1 /-14.9 \mathrm{mmHg}$ with valsartan/HCTZ, -20.1/-10.8 mmHg with valsartan $80 \mathrm{mg}$, and $-23.1 /-11.7 \mathrm{mmHg}$ with valsartan $160 \mathrm{mg}$. Results favored combination therapy over either dose of valsartan alone $(P<0.05)$.

The PROMPT study compared the antihypertensive efficacy of valsartan/HCTZ (first- and second-line use) and amlodipine/HCTZ for maximizing BP control in 1285 patients with uncontrolled hypertension. ${ }^{46}$ Patients who had mild hypertension (SBP/DBP 140-159/90-99 mmHg) and were naïve to antihypertensive therapy started on valsartan $160 \mathrm{mg}$ or amlodipine $5 \mathrm{mg}$. Treatment-naïve patients with moderate hypertension (SBP/DBP 160-179/100-109 mmHg) and those uncontrolled on current antihypertensive monotherapy started on valsartan/HCTZ 160/12.5 mg or amlodipine $10 \mathrm{mg}$. At 4, 8, and 11 weeks, patients not achieving BP control were uptitrated (maximum: valsartan/HCTZ 320/25 mg or amlodipine/HCTZ 10/25 mg). Uptitration was mandatory for MSSBP/MSDBP $\geq 140 / 90 \mathrm{mmHg}$. The treatment duration was 14 weeks. BP control rates (MSSBP/MSDBP $<140 / 90 \mathrm{mmHg}$ ) at 14 weeks, the primary endpoint, were $78.8 \%$ with valsartan-based treatment and $67.8 \%$ with amlodipine-based treatment $(P<0.0001)$. Significant differences in favor of valsartan-based therapy were observed as early as 8 weeks (70.3\% vs $64.5 \%, P<0.05)$. Results were consistent, regardless of whether patients were treatment naïve or had failed previous monotherapy. Thus, the valsartan-based strategy was superior to the amlodipine-based strategy for achieving BP control.

\section{Moderate hypertension}

The EVALUATE study examined the antihypertensive efficacy of valsartan/HCTZ and amlodipine/HCTZ on the reduction of ambulatory BP (ABP) in 482 patients with moderate hypertension (SBP 160-200 mmHg). ${ }^{47}$ EVALUATE was designed to mirror the treatment arms of the VALUE outcomes study. In VALUE, there was greater BP reduction observed in the amlodipine arm compared with the valsartan arm in the first 6 months that accounted for the differences in outcomes favoring amlodipine. ${ }^{27}$ It is discussed that these findings may have been due to slow titration and use of a less than maximal dose of valsartan $(160 \mathrm{mg}),{ }^{48}$ which is half of what is currently considered as the maximum recommended dose. Thus, in EVALUATE, patients received valsartan $160 \mathrm{mg}$ force-titrated to valsartan/HCTZ 160/12.5 mg at 2 weeks and 320/25 mg at 6 weeks or amlodipine $5 \mathrm{mg}$ force-titrated to $10 \mathrm{mg}$ at 2 weeks and amlodipine/HCTZ 10/25 mg at 6 weeks. ${ }^{47}$ The treatment duration was 10 weeks. The primary endpoint was change in mean 24-hour ambulatory SBP (ASBP) from baseline to 10 weeks. Changes in mean 24-hour ASBP/ambulatory DBP (ADBP) from baseline to 10 weeks were $-21.1 /-12.5 \mathrm{mmHg}$ with valsartan/HCTZ and -18.1/-9.9 mmHg with amlodipine/ HCTZ $(P<0.01)$. As shown in Figure 2, valsartan/HCTZ provided greater antihypertensive efficacy over the entire 24-hour monitoring period. ABP control rates (mean 24-hour ASBP/ADBP $<130 / 80 \mathrm{mmHg}$ ) at 10 weeks were $54.3 \%$ with valsartan/HCTZ and $42.7 \%$ with amlodipine/HCTZ $(P<0.05)$. These data show that valsartan/HCTZ provides reduction in ABP that is superior to that achieved with amlodipine/HCTZ.

\section{Severe hypertension}

In the CDITT study, the antihypertensive efficacy of initiating therapy with combination valsartan/HCTZ versus valsartan monotherapy was examined in 608 patients with severe hypertension, defined as SBP $\geq 140 \mathrm{mmHg}$ and $<200 \mathrm{mmHg}$ plus DBP $\geq 110 \mathrm{mmHg}$ and $<120 \mathrm{mmHg} .{ }^{49}$ Patients received valsartan/HCTZ 160/12.5 mg force-titrated to 160/25 mg at 2 weeks and 320/25 mg at 4 weeks or valsartan $160 \mathrm{mg}$ forcetitrated to $320 \mathrm{mg}$ at 2 weeks and sham-titrated to $320 \mathrm{mg}$ at 4 weeks. The treatment duration was 6 weeks. BP control rates (MSSBP/MSDBP $<140 / 90 \mathrm{mmHg}$ ) at 4 weeks, the primary endpoint, were $39.6 \%$ with valsartan/HCTZ and $21.8 \%$ with valsartan $(P<0.0001)$. The corresponding results at 6 weeks were $48.2 \%$ and $27.2 \%(P<0.0001)$. Changes in MSSBP/ MSDBP from baseline to 4 weeks and 6 weeks are shown in Figure 3. Control rates and BP reductions consistently favored combination therapy over monotherapy, regardless of age ( $<65$ or $\geq 65$ years), race (white or black), or severity of baseline MSSBP ( $<180$ or $\geq 180 \mathrm{mmHg}$ ).

\section{Influence of valsartan on the metabolic effects of HCTZ in the combination valsartan/HCTZ} The MADE-ITT study evaluated the effects of valsartan and HCTZ alone and in combination on insulin sensitivity and inflammatory/metabolic biomarkers in 566 patients 


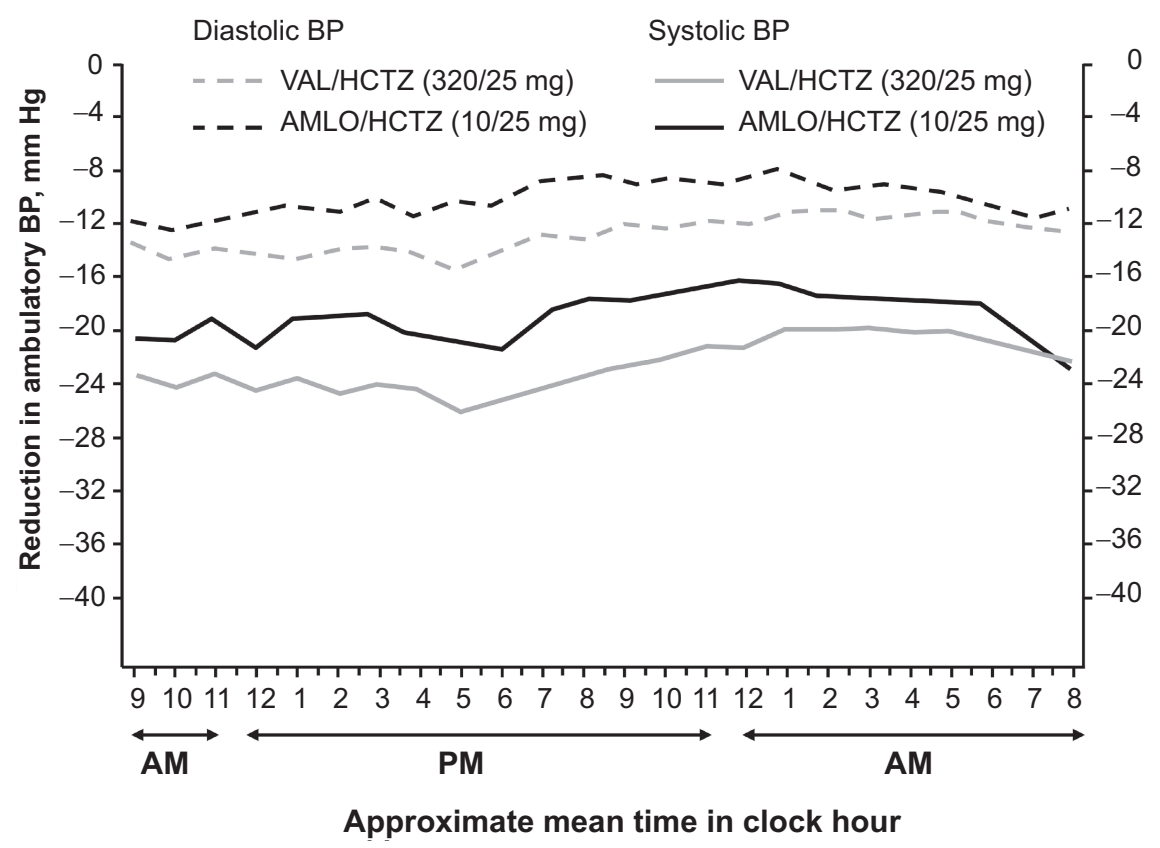

Figure 2 Changes in ambulatory systolic and diastolic blood pressure from baseline over a 24-hour period after 10 weeks of treatment in a study of 482 patients with moderate hypertension. Reprinted with permission from Lacourcière Y,Wright Jr JT, Samuel R, Zappe D, Purkayastha D, Black HR. Effects of force-titrated valsartan/hydrochlorothiazide versus amlodipine/hydrochlorothiazide on ambulatory blood pressure in patients with stage 2 hypertension: the EVALUATE study. Blood Press Monit. 2009; I4(3):I I2-I20. ${ }^{47}$ Copyright (C) 2009 Lippincott Williams \& Wilkins.

Abbreviations: AMLO, amlodipine; BP, blood pressure; HCTZ, hydrochlorothiazide; VAL, valsartan.

with prediabetes, obesity, hypertension (SBP/DBP 130-160/85-100 mmHg) and the cardiometabolic syndrome. ${ }^{50}$ Patients received valsartan/HCTZ 160/12.5 mg force-titrated to $320 / 25 \mathrm{mg}$ at 2 weeks, valsartan $160 \mathrm{mg}$ force-titrated to $320 \mathrm{mg}$ at 2 weeks, or HCTZ $12.5 \mathrm{mg}$ force-titrated to $25 \mathrm{mg}$ at 2 weeks. The treatment duration was 16 weeks. There were no significant differences among the 3 treatment groups for the primary endpoint, which was change in homeostasis model assessment-insulin resistance (HOMA-IR) from baseline to 16 weeks. However, valsartan attenuated the negative metabolic effects of HCTZ (increases in triglyceride and hemoglobin). At 16 weeks, treatment with HCTZ increased triglyceride levels by $0.3 \mathrm{mmol} / \mathrm{L}$ and hemoglobin $\mathrm{A}_{1 \mathrm{c}}$ levels by $0.2 \%$, whereas valsartan and valsartan/HCTZ had less of an effect on these parameters. Changes in MSSBP/MSDBP from baseline to 16 weeks were significantly greater with combination therapy $(-20 /-12 \mathrm{mmHg})$ than with valsartan $(-14 /-9 \mathrm{mmHg})$ or HCTZ $(-12 /-7 \mathrm{mmHg})(P<0.0001)$. These findings support the initial use of valsartan/HCTZ in this high-risk population.

The VITAE study was undertaken to confirm the findings from MADE-ITT using actual glucose and insulin measures (both fasting and 2 hour). ${ }^{51}$ Specifically, the metabolic and antihypertensive effects of valsartan/HCTZ versus amlodipine/HCTZ in 412 prediabetic, obese patients with mild to moderate hypertension (SBP/DBP 150-179/<110 mmHg) were investigated. Patients received valsartan/HCTZ $160 / 12.5 \mathrm{mg}$ force-titrated to $320 / 12.5 \mathrm{mg}$ at 4 weeks and $320 / 25 \mathrm{mg}$ at 8 weeks, or HCTZ $12.5 \mathrm{mg}$ force-titrated to $25 \mathrm{mg}$ at 4 weeks, amlodipine/HCTZ 5/25 mg at 8 weeks, and amlodipine/HCTZ 10/25 mg at 12 weeks. The treatment duration was 16 weeks. The primary endpoint was change in MSSBP from baseline. Changes in MSSBP/MSDBP from baseline to 16 weeks were $-30.6 /-14.0 \mathrm{mmHg}$ with valsartan/HCTZ and -28.3/-12.7 $\mathrm{mmHg}$ with amlodipine/ HCTZ $(P=$ NS). Fasting and 2-hour glucose increased with amlodipine/HCTZ compared with valsartan/HCTZ $(P<0.01)$, resulting in a greater percentage of patients with impaired fasting glucose or impaired oral glucose tolerance test. In the valsartan/HCTZ group, the percentage of patients with impaired fasting glucose was 34\% at baseline and 38\% at 16 weeks. Corresponding results for impaired oral glucose tolerance test were $36 \%$ and $29 \%$. Conversely, the percentage of amlodipine/HCTZ-treated patients with impaired fasting glucose increased from $38 \%$ to $50 \%$ during this time as did the percentage with impaired oral glucose tolerance test (from $34 \%$ to $48 \%$ ). New-onset diabetes occurred in more patients receiving amlodipine/HCTZ compared with valsartan/HCTZ (11\% vs $2 \%, P<0.05)$. Thus, compared with amlodipine/ HCTZ, valsartan/HCTZ reduced progression towards impaired fasting glucose, impaired glucose tolerance, and new-onset diabetes in this high-risk population. 

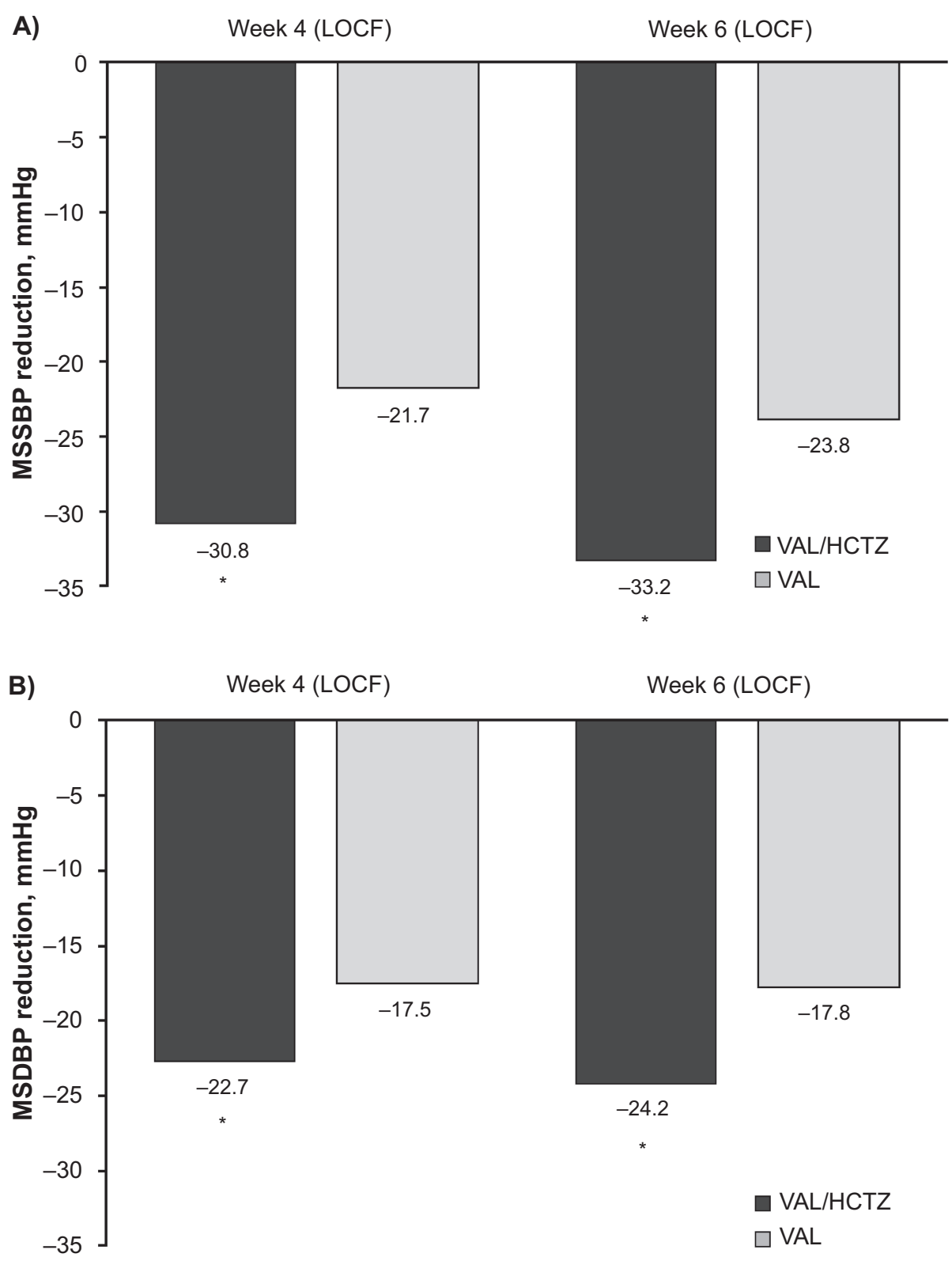

Figure 3 Changes in A) mean seated systolic blood pressure (MSSBP) and B) mean seated diastolic blood pressure (MSDBP) from baseline after 4 and 6 weeks of treatment in a study of 608 patients with severe hypertension.

$* P<0.000$ I vs valsartan monotherapy. Reprinted with permission from Calhoun DA, Glazer RD, Pettyjohn FS, Coenen PD, ZhaoY, Grosso A. Efficacy and tolerability of combination therapy with valsartan/hydrochlorothiazide in the initial treatment of severe hypertension. Curr Med Res Opin. 2008;24(8):2303-23।I.49 Copyright @ 2008 Informa Healthcare. Abbreviations: HCTZ, hydrochlorothiazide; LOCF, last observation carried forward; VAL, valsartan.

\section{Switch study}

Diuretics are recommended as first-line therapy for the treatment of hypertension., ${ }^{2,15}$ A study was conducted to assess whether, in patients uncontrolled on diuretic monotherapy, it is a better strategy to switch to dual therapy or double the dose of diuretic..$^{52}$ The Val-DICTATE study included 291 patients with hypertension whose BP remained uncontrolled (SBP $>140$ and $<180 \mathrm{mmHg}$ plus $\mathrm{DBP}>90$ and $<110 \mathrm{mmHg}$ ) after 4 weeks of therapy with low-dose HCTZ (12.5 mg). These patients received valsartan/HCTZ
$(160 / 12.5 \mathrm{mg})$ or double the dose of HCTZ $(25 \mathrm{mg})$ for another 4 weeks. At study end, a significantly greater percentage of patients achieved the BP goal (MSSBP/ MSDBP $<140 / 90 \mathrm{mmHg}$ ), the primary endpoint, in the valsartan/HCTZ group compared with the high-dose HCTZ group (36.6\% vs $15.9 \%, P<0.0001)$. Similarly, changes in MSSBP/MSDBP at study end were significantly greater in the combination therapy arm compared with the diuretic monotherapy arm $(-12.4 /-7.5 \mathrm{mmHg}$ vs $-5.6 /-2.1 \mathrm{mmHg}$, $P<0.0001)$. Thus, in patients whose BP was inadequately 
controlled on low-dose HCTZ (12.5 mg), switching to valsartan/HCTZ 160/12.5 mg was a better antihypertensive strategy than doubling the dose of HCTZ.

\section{Other studies}

The results of several open-label studies also support the antihypertensive efficacy of valsartan/HCTZ. ${ }^{44,53-58}$

\section{Safety and tolerability}

The combination of valsartan/HCTZ is well tolerated and adverse events are generally mild and transient. A meta-analysis of the results of 9 randomized, double-blind, placebo-controlled, hypertension studies $(\mathrm{N}=4278)$ of oncedaily valsartan 80,160 , or $320 \mathrm{mg}$ or valsartan/HCTZ 80/12.5, $160 / 12.5 \mathrm{mg}, 160 / 25 \mathrm{mg}, 320 / 12.5 \mathrm{mg}$, or $320 / 25 \mathrm{mg}$ given for 4 to 8 weeks found that the most common adverse event was dizziness $(7.3 \%$ to $16.0 \%$ in the valsartan/HCTZ groups vs $2.4 \%$ to $5.2 \%$ with valsartan monotherapy and $2.8 \%$ with placebo). ${ }^{59}$ The incidence of headache was similar across all dose groups including placebo. The rate of discontinuation due to adverse events was generally low at all dose levels (eg, 3.0\% with valsartan/HCTZ 320/25 mg vs $2.7 \%$ with placebo). ${ }^{59}$ Data suggest that the incidence of hypokalemia may be lower with valsartan/HCTZ compared with HCTZ alone ( $1.8 \%$ to $6.1 \%$ vs $7.1 \%$ to $13.3 \%),{ }^{44}$ and that valsartan may attenuate the negative metabolic effects of HCTZ in patients with prediabetes, obesity, hypertension, and the cardiometabolic syndrome (see MADE-ITT study results described previously). ${ }^{50}$ Valsartan/HCTZ was associated with a lower incidence of peripheral edema compared with amlodipine/HCTZ across the studies presented previously ( $1.5 \%$ to $3.3 \%$ vs $9.7 \%$ to $22.4 \%) .{ }^{46,47,51}$

\section{Amlodipine/valsartan}

The combination of amlodipine/valsartan is indicated for the treatment of hypertension in patients not adequately controlled on monotherapy and as initial therapy in patients likely to need multiple drugs to achieve their BP goals. All studies discussed in this section employed a randomized, double-blind design and, in all cases, study medication was administered once daily. A section on safety and tolerability follows the discussion of efficacy.

\section{Factorial phase III studies in mild to moderate hypertension}

Two placebo-controlled studies compared the antihypertensive efficacy of various combinations of amlodipine/valsartan versus monotherapy with these agents in 3161 patients with mild to moderate hypertension (DBP $\geq 95$ and $<110 \mathrm{mmHg}) .{ }^{60}$ In study 1, 15 factorial treatment regimens were used and, in study 2, 6 regimens were used. The primary endpoint was change in MSDBP from baseline to 8 weeks. Apart from a few combinations that included amlodipine $2.5 \mathrm{mg}$, the combination regimens in both studies were associated with significantly greater reductions in MSSBP and MSDBP compared with their individual components and placebo $(P<0.05)$. A positive dose-response relationship was observed for all combinations, and the highest response rate $(\mathrm{MSDBP}<90 \mathrm{mmHg}$ or $\mathrm{a} \geq 10 \mathrm{mmHg}$ reduction from baseline) in study 1 was associated with the highest dose of combination therapy (91.3\% for amlodipine/valsartan $5 / 320 \mathrm{mg}$ ). In contrast, amlodipine $5 \mathrm{mg}$, valsartan $320 \mathrm{mg}$, and placebo as monotherapy were associated with response rates of $71.9 \%, 73.4 \%$, and $40.9 \%$, respectively. In study 2 , the 2 combination therapy regimens were associated with similar response rates (amlodipine/valsartan 10/160 mg, 88.5\%; amlodipine/valsartan 10/320 mg, 87.5\%). Amlodipine $10 \mathrm{mg}$ was associated with a response rate of $86.9 \%$; valsartan $160 \mathrm{mg}$ and $320 \mathrm{mg}$ were associated with response rates of $74.9 \%$ and $72.0 \%$, respectively. Placebo was associated with a response rate of $49.3 \%{ }^{60}$ Subgroup analyses of the results of these studies, conducted according to the severity of hypertension (mild or moderate), age ( $<65$ or $\geq 65$ years) and race (white or black), showed that reductions in MSSBP and MSDBP in the various subgroups were consistent with the findings from the overall study population. ${ }^{61}$

\section{Phase IV studies in moderate hypertension}

Destro and colleagues investigated the antihypertensive efficacy of amlodipine/valsartan and amlodipine alone in 646 patients with moderate hypertension ( $\mathrm{SBP} \geq 160 \mathrm{mmHg}$ and $<200 \mathrm{mmHg}$ ). ${ }^{62}$ Patients received amlodipine/valsartan $5 / 160 \mathrm{mg}$ force-titrated to $10 / 160 \mathrm{mg}$ at 2 weeks or amlodipine $5 \mathrm{mg}$ force-titrated to $10 \mathrm{mg}$ at 2 weeks. HCTZ was optionally added at 4 weeks in patients if MSSBP $\geq 130 \mathrm{mmHg}$. The treatment duration was 8 weeks. Changes in MSSBP from baseline to 4 weeks (prior to possible addition of HCTZ), the primary endpoint, were $-30.1 \mathrm{mmHg}$ with amlodipine/valsartan and $-23.5 \mathrm{mmHg}$ with amlodipine $(P<0.0001)$. In patients with baseline MSSBP $\geq 180 \mathrm{mmHg}$, the corresponding results were $-40.1 \mathrm{mmHg}$ and $-31.7 \mathrm{mmHg}(P<0.01)$. Results were consistent across various patient subgroups, including patients with diabetes, the elderly ( $\geq 65$ years), patients with isolated systolic hypertension, those with body mass index $\geq 30 \mathrm{~kg} / \mathrm{m}^{2}$, and patients of different races/ ethnicity (white, black, or Hispanic) (Figure 4). BP control 


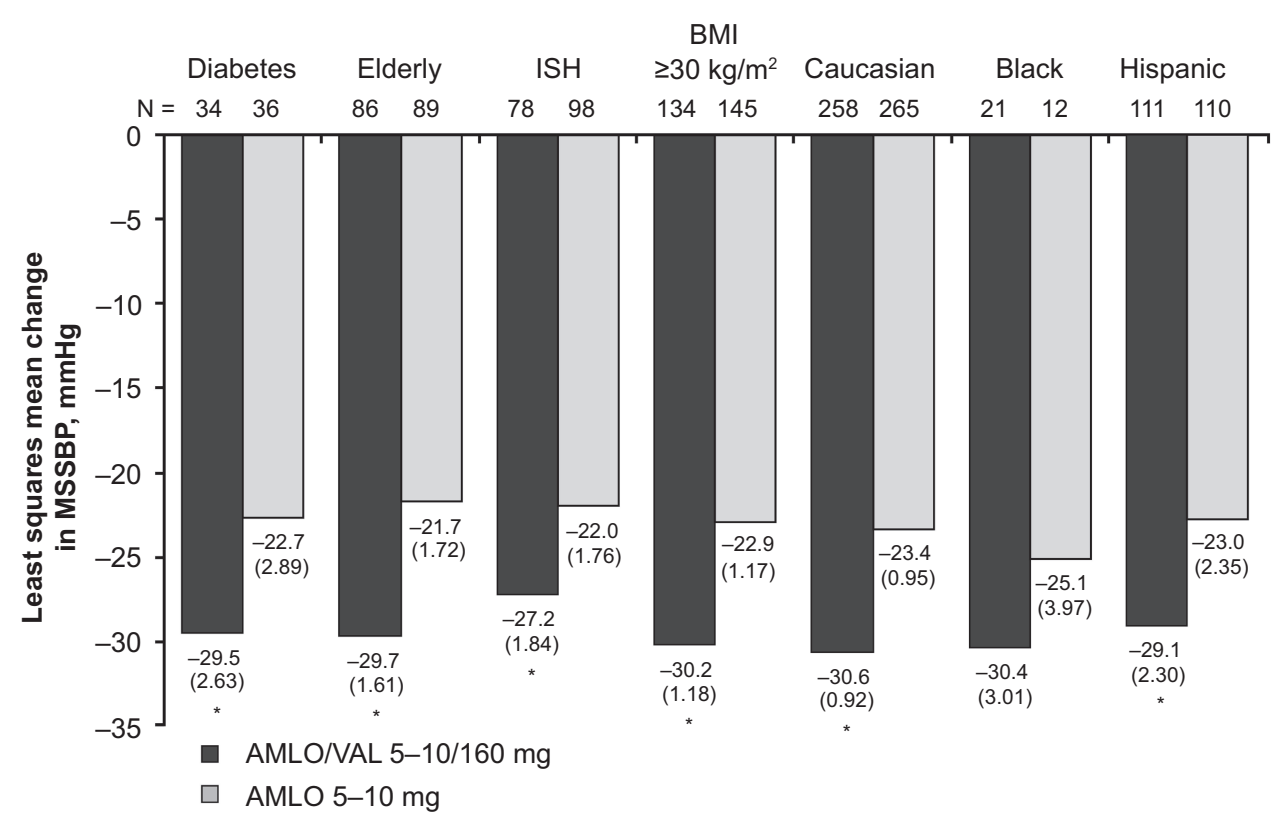

Figure 4 Least-squares mean changes in mean seated systolic blood pressure (MSSBP) from baseline after 4 weeks of treatment across various patient subgroups with moderate hypertension. Elderly patients were $\geq 65$ years of age.

Notes: Values in parentheses denote SEM.

$* P<0.05$ vs amlodipine. Reprinted from Destro M, LuckowA, Samson M, KandraA, Brunel P.Efficacy and safety of amlodipine/valsartan compared with amlodipine monotherapy in patients with stage 2 hypertension: a randomized, double-blind, multicenter study: the EX-EFFeCTS Study.J Am Soc Hypertens. 2008;2(4):294-302.62 Copyright @ 2008 with permission from Elsevier.

Abbreviations: AMLO, amlodipine; BMI, body mass index; ISH, isolated systolic hypertension; SEM, standard error of the mean; VAL, valsartan.

rates $(\mathrm{MSSBP} / \mathrm{MSDBP}<140 / 90 \mathrm{mmHg}$ ) at 4 weeks were $45.3 \%$ with amlodipine/valsartan and $23.8 \%$ with amlodipine $(P<0.0001)$.

Poldermans and colleagues examined the antihypertensive efficacy of amlodipine/valsartan compared with lisinopril/HCTZ in 130 patients with moderate hypertension (DBP $\geq 110 \mathrm{mmHg}$ and $<120 \mathrm{mmHg}$ ). ${ }^{63}$ Patients received amlodipine/valsartan $5 / 160 \mathrm{mg}$ or lisinopril/ HCTZ 10/12.5 mg for 2 weeks. Thereafter, up-titration to $10 / 160 \mathrm{mg}$ and $20 / 12.5 \mathrm{mg}$, respectively, occurred for MSDBP $\geq 90 \mathrm{mmHg}$. The treatment duration was 6 weeks. The primary endpoint was safety, but post-hoc efficacy endpoints included change in MSSBP/MSDBP from baseline and BP control rates (MSSBP/MSDBP < 140/90 mmHg). Both regimens were deemed efficacious. Changes in MSSBP/ MSDBP from baseline to study end were $-35.8 /-28.6 \mathrm{mmHg}$ with amlodipine/valsartan and $-31.8 /-27.6 \mathrm{mmHg}$ with lisinopril/HCTZ. BP control rates at this time were $67.2 \%$ and $56.1 \%$, respectively.

\section{Phase IV study in black patients with moderate hypertension}

Blacks patients are usually considered a difficult-totreat population. The EX-STAND study assessed the antihypertensive efficacy of initiating treatment with amlodipine/valsartan compared with amlodipine monotherapy in 572 black patients with moderate hypertension (SBP $\geq 160$ and $<200 \mathrm{mmHg}$ ). ${ }^{64}$ Patients received amlodipine/valsartan 5/160 mg force-titrated to $10 / 160 \mathrm{mg}$ at 2 weeks or amlodipine $5 \mathrm{mg}$ force-titrated to $10 \mathrm{mg}$ at 2 weeks. If MSSBP was $\geq 130 \mathrm{mmHg}$ at 4 weeks, the doses in the amlodipine/valsartan arm were increased to $10 / 320 \mathrm{mg}$ and placebo was added to the amlodipine arm. At 8 weeks, HCTZ was optionally added to both treatment groups for patients with MSSBP $\geq 130 \mathrm{mmHg}$. The treatment duration was 12 weeks. Changes in MSSBP from baseline to 8 weeks (prior to possible addition of HCTZ), the primary endpoint, were $-33.3 \mathrm{mmHg}$ with amlodipine/valsartan and $-26.6 \mathrm{mmHg}$ with amlodipine $(P<0.0001)$. Significant differences in favor of initial combination therapy were observed as early as 2 weeks and also were seen at 4 and 12 weeks (Figure 5). Combination therapy provided greater reductions in MSSBP from baseline to 8 weeks across various patient subgroups, including the elderly ( $\geq 65$ years), patients with isolated systolic hypertension, diabetics, those with body mass index $\geq 30 \mathrm{~kg} / \mathrm{m}^{2}$, patients who were black/ Hispanic, and patients with baseline MSSBP $\geq 180 \mathrm{mmHg}$. BP control rates (MSSBP/MSDBP $<140 / 90 \mathrm{mmHg}$ ) at 


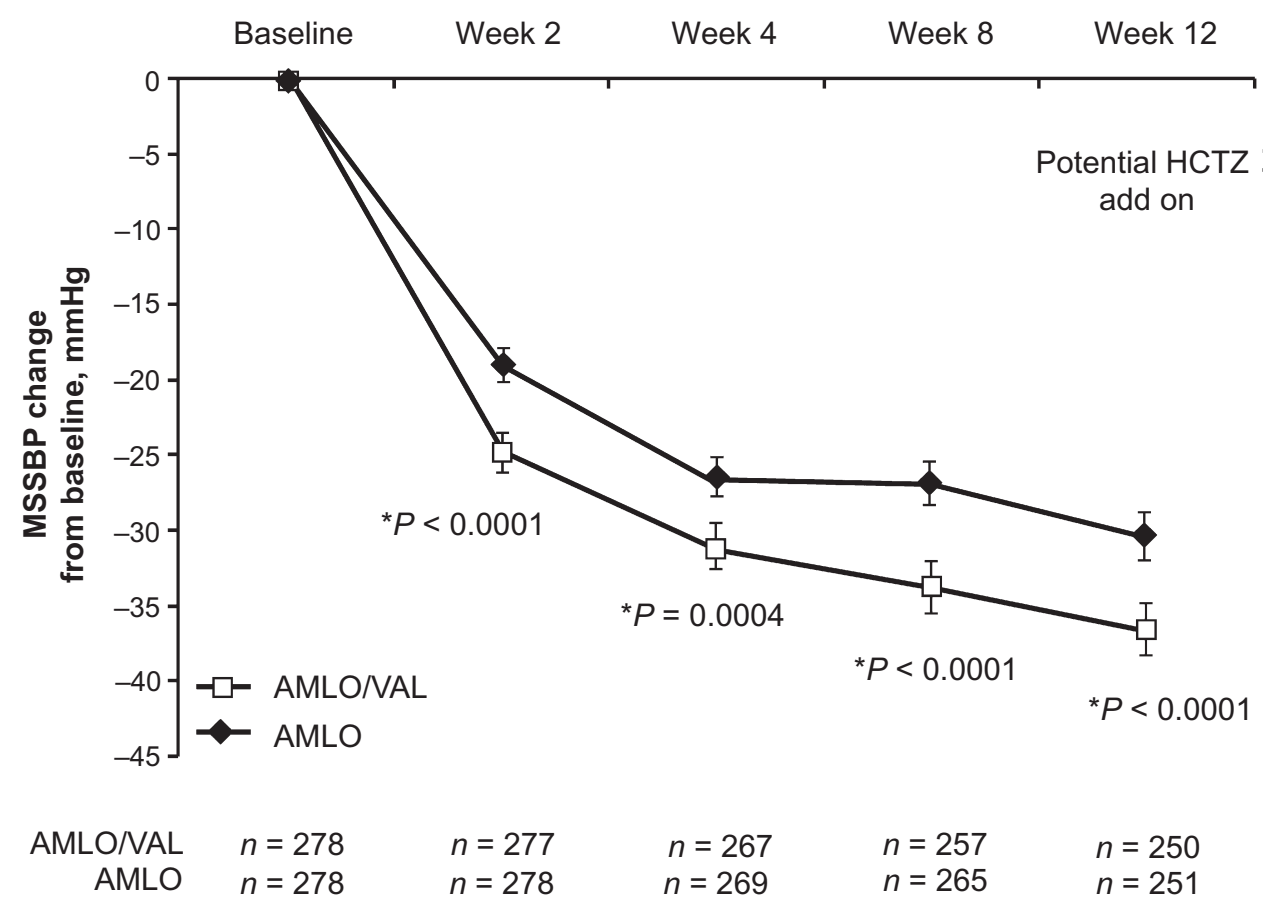

$n$ is the number of patients at each week. Error bars denote SEM

$P$-value refers to comparison of monotherapy with combination therapy.

Figure 5 Changes in mean seated systolic blood pressure (MSSBP) over time in black patients with moderate hypertension. Reprinted by permission from Macmillan Publishers Ltd: Flack JM, Calhoun DA, Satlin L, Barbier M, Hilkert R, Brunel P. Efficacy and safety of initial combination therapy with amlodipine/valsartan compared with amlodipine monotherapy in black patients with stage 2 hypertension: the EX-STAND study.J Hum Hypertens. 2009;23(7):479-489.64 Copyright (C) 2009.

Abbreviations: AMLO, amlodipine; HCTZ, hydrochlorothiazide; SEM, standard error of the mean; VAL, valsartan.

8 weeks were $49.8 \%$ with amlodipine/valsartan and $30.2 \%$ with amlodipine $(P<0.0001)$.

\section{Phase IIIB-IV switch studies in patients previously uncontrolled with monotherapy}

Allemann and colleagues evaluated the antihypertensive efficacy of a strategy involving a direct switch to amlodipine/ valsartan in 894 patients whose BP was uncontrolled by previous monotherapy (EX-FAST study). ${ }^{65}$ Patients were switched directly to amlodipine/valsartan 5/160 $\mathrm{mg}$ or $10 / 160 \mathrm{mg}$ for 16 weeks. At 8 weeks, HCTZ was added to both treatment groups for patients whose BP was not controlled (MSSBP/MSDBP $\geq 140 / 90 \mathrm{mmHg}$ in nondiabetic patients, $\geq 130 / 80 \mathrm{mmHg}$ in patients with diabetes). $\mathrm{BP}$ control rates at 16 weeks, the primary endpoint, were similar in the 2 treatment groups: $72.7 \%$ with amlodipine/ valsartan 5/160 mg ( \pm HCTZ) and 74.8\% with amlodipine/ valsartan 10/160 mg ( \pm HCTZ). Incremental reductions in MSSBP/MSDBP from baseline to 16 weeks were significantly greater with the higher dose $(-20.0 /-11.6 \mathrm{mmHg})$ than with the lower dose $(-17.5 /-10.4 \mathrm{mmHg})(P<0.01)$. BP control rates at 8 weeks (prior to possible addition of HCTZ) also were significantly greater with the higher dose $(76.4 \%)$ than with the lower dose $(71.1 \%)(P<0.05)$. Subgroup analysis revealed that the antihypertensive efficacy of amlodipine/valsartan was well maintained regardless of previous antihypertensive monotherapy (Figure 6), baseline hypertension severity, diabetic status, body mass index, age, gender, or race.

The antihypertensive efficacy of switching patients whose BP was not controlled on valsartan $160 \mathrm{mg}$ monotherapy to amlodipine/valsartan 5/160 mg or 10/160 mg was studied in 947 patients with mild or moderate hypertension (DBP $\geq 95$ and $<110 \mathrm{mmHg}$ ). ${ }^{66}$ Patients received amlodipine/valsartan $5 / 160 \mathrm{mg}$, amlodipine/valsartan 10/160 mg, or continued on valsartan $160 \mathrm{mg}$ for 8 weeks. The primary endpoint was change in MSDBP from baseline to study end. Changes in MSSBP/MSDBP from baseline to study end were significantly greater with lower-dose combination therapy $(-12.2 /-9.6 \mathrm{mmHg})$ and higher-dose combination therapy $(-14.3 /-11.5 \mathrm{mmHg})$ compared with valsartan alone $(-8.3 /-6.7 \mathrm{mmHg})(P<0.0001)$. The $10 / 160 \mathrm{mg}$ combination showed significantly greater reductions in MSSBP and MSDBP than the $5 / 160 \mathrm{mg}$ combination $(P<0.05)$. Response rates (MSDBP $<90 \mathrm{mmHg}$ or $\geq 10-\mathrm{mmHg}$ reduction from baseline) at endpoint were significantly greater in the combination therapy groups $(68 \%$ with $5 / 160 \mathrm{mg}$, 


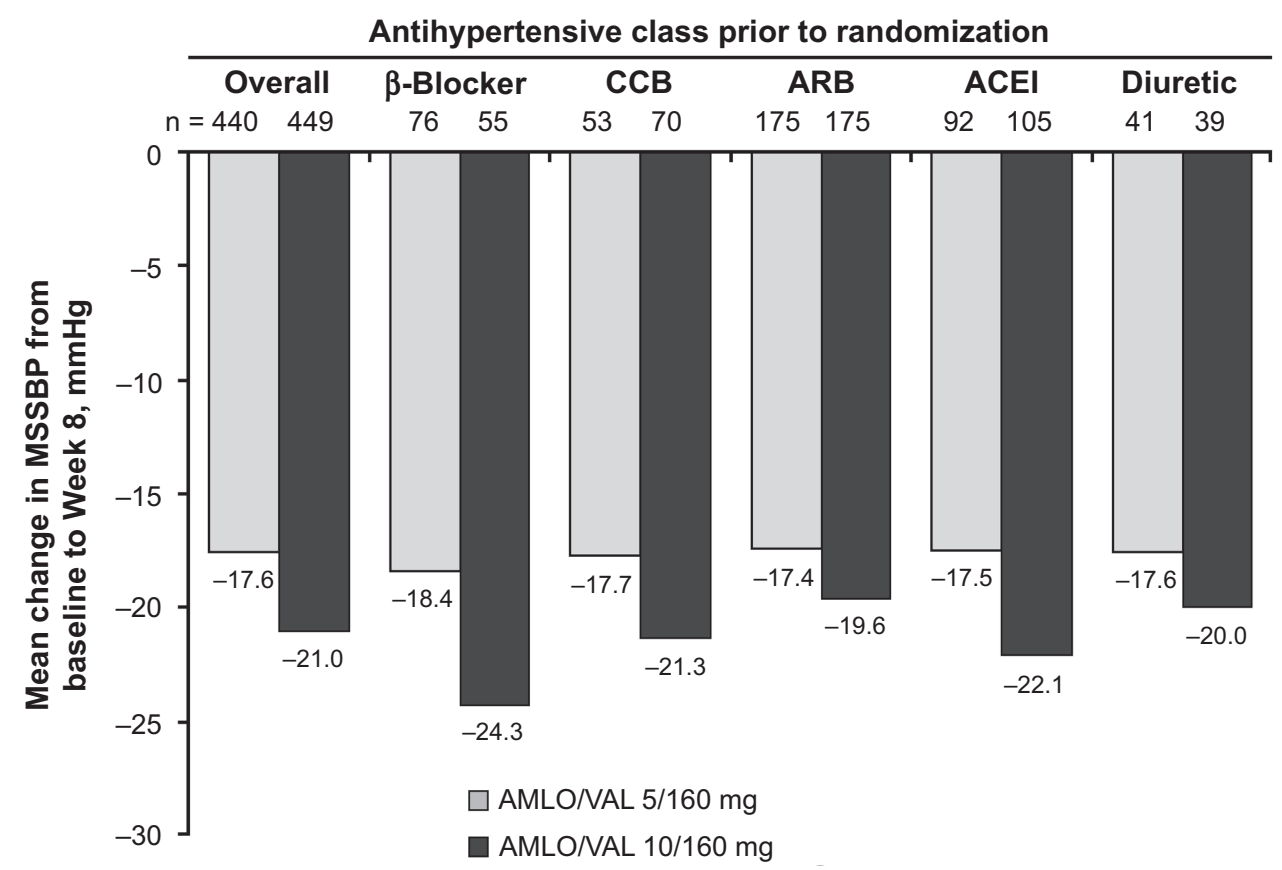

Figure 6 Changes in mean seated systolic blood pressure (MSSBP) from baseline after 8 weeks of treatment in patients whose blood pressure was uncontrolled on previous antihypertensive monotherapy. Results are shown by previous antihypertensive monotherapy. Reprinted with permission from Allemann Y, Fraile B, Lambert M, Barbier M, Ferber P, Izzo JL Jr. Efficacy of the combination of amlodipine and valsartan in patients with hypertension uncontrolled with previous monotherapy: the Exforge in Failure after Single Therapy (EX-FAST) study.J Clin Hypertens (Greenwich). 2008; 10(3): 185-194. ${ }^{65}$ Copyright () 2008 John Wiley and Sons, Inc.

Abbreviations: ACEI, angiotensin-converting enzyme inhibitor; AMLO, amlodipine; $A R B$, angiotensin receptor blocker; CCB, calcium channel blocker; $V A L$, valsartan.

$81 \%$ with $10 / 160 \mathrm{mg}$ ) than in the monotherapy group (57\%) $(P<0.01)$. Both combination therapies were more effective than monotherapy regardless of age ( $<65$ or $\geq 65$ years).

\section{Other studies}

The results of several open-label studies also support the antihypertensive efficacy of amlodipine/valsartan. ${ }^{67-72}$ Of note, one of the trial designs involved switching patients whose BP was not controlled on a free combination (amlodipine plus olmesartan) to a single-pill combination (amlodipine plus valsartan). ${ }^{71}$ Treatment with the singlepill combination was associated with a further reduction in BP of 7.9/9.1 mmHg, with $42 \%$ of previously uncontrolled patients achieving BP $<140 / 90 \mathrm{mmHg}$. The authors concluded that these results may have been related, at least in part, to improved patient compliance, although this was not specifically assessed in the study. The issues of compliance with antihypertensive therapy and the potential role of singlepill combination therapy are discussed in more detail later.

\section{Safety and tolerability}

Amlodipine/valsartan was well tolerated in the abovementioned clinical studies. Most adverse events were mild or moderate in severity and did not result in discontinuation.
Overall, the most frequent adverse event was peripheral edema, which is a well-known side effect of CCBs. CCBs cause greater dilation of the arteriolar rather than the venous circulation, giving rise to an increased transcapillary gradient and capillary leakage. ${ }^{73}$ The addition of a RAAS blocker may help to negate this effect because it causes dilation of both arterial and venous capillary beds, thus bringing transcapillary pressure back to normal. One randomized, double-blind study assessed the incidence of peripheral edema as a co-primary endpoint in 1183 patients not adequately controlled on amlodipine $5 \mathrm{mg} .{ }^{74}$ Peripheral edema was evaluated at every clinic visit and was based on spontaneous reports by the patients and on the presence of signs of edema on physical examination of the patient by the investigator. Over the first 8 weeks of the study, patients received either amlodipine/ valsartan 5/160 $\mathrm{mg}$ or double the dose of amlodipine $(10 \mathrm{mg})$. During this time, peripheral edema was reported in $31.1 \%$ of patients on high-dose amlodipine compared with only $6.6 \%$ of patients on combination therapy $(P<0.001)$. After 8 weeks of therapy, 484 patients previously on high-dose amlodipine were switched to amlodipine/valsartan 5/160 mg for another 4 weeks. Of the 79 patients who had peripheral edema entering the switch phase, 44 (56\%) had resolution of this adverse event during the switch phase. In the double-blind 
studies described previously, peripheral edema was reported in a slightly higher percentage of amlodipine-treated ( \pm HCTZ) patients $(8.7 \%$ to $17.6 \%$ ) than amlodipine/ valsartan-treated ( \pm HCTZ) patients $(5.0 \%$ to $16.7 \%)$. The occurrence of peripheral edema appeared to be related to the dose of amlodipine. The incidence of peripheral edema was low among patients treated with valsartan monotherapy $(1.3 \%$ to $2.1 \%)$ or placebo $(3 \%)$ in the same studies.

\section{Patient-focused perspectives}

Much of the difficulty of controlling high BP may be due to poor persistence and adherence with therapy as patients who are adherent are more likely to have good BP control. ${ }^{75}$ Poor adherence with antihypertensive therapy may lead to extra medical consultations, higher doses, or an increase in the number of medications used and possibly increased morbidity and mortality, loss of productivity, and increased health care costs. Analyses of data from the Integrated Healthcare Information Solutions (IHCIS) National Managed Care Benchmark Database indicate that patient compliance improves with simplification of pharmacotherapeutic approaches, ${ }^{76}$ and that use of single-pill combination therapy may improve adherence and persistence and have a positive economic impact. ${ }^{77}$

For example, an analysis of the impact of multiple combination therapies on medication possession ratios (MPRs) in an antihypertensive-naive population was conducted using IHCIS data from patients treated with valsartan or valsartan/HCTZ in a single-pill combination plus amlodipine (2-pill therapy) compared with patients who received 3-pill therapy with valsartan plus HCTZ plus amlodipine. ${ }^{76}$ Data from 908 patients were included (2-pill therapy with valsartan plus amlodipine, $n=224$; 2-pill therapy with valsartan/HCTZ plus amlodipine, $n=619$; and 3-pill therapy with valsartan plus HCTZ plus amlodipine, $\mathrm{n}=65$ ) over a 1-year study period. MPR values obtained were $75.4 \%, 73.1 \%$, and $60.5 \%$, respectively $(P<0.01)$, and it was found that MPR improved with age $(69.6 \%$ in the subset aged 18 to $<36$ years vs $75.2 \%$ in the subset aged $\geq 64$ years, $P<0.05$ ). Thus, in these antihypertensive-naive patients with hypertension, MPR decreased with the increase in tablets per regimen. Improved MPR was correlated with increasing age, and the results suggested that patient compliance improved with simplified pharmacotherapeutic approaches.

In addition, medical and prescription claims for hypertensive patients were identified from the IHCIS National Managed Care Benchmark Database via a retrospective cohort analysis to assess medication adherence, persistence, and costs between cohorts of patients in managed care settings using a single-pill combination of valsartan/HCTZ or the individual components. ${ }^{77}$ Patients who were studied had at least 110 days prior to start of study medications during which no other antihypertensive medications were prescribed, were followed for 12 months, and claims for 8711 adult patients were analyzed. Most individuals used a single-pill combination product $(\mathrm{n}=8150,93.6 \%)$ versus the individual components $(\mathrm{n}=561,6.4 \%)$. A random sample of 1628 of the single-pill combination patients showed improved values for medication adherence compared with the individual components group ( $62 \%$ vs $53 \%, P<0.001)$, and persistence values were improved at both 180 days (73\% vs $28 \%, P<0.001)$ and 365 days $(54 \%$ vs $19 \%$, $P<0.001)$. Both prescription drug costs and medical costs were significantly lower in the single-pill combination cohort. Over 1 year, the mean total prescription costs for the individual components versus the single-pill combination were US $\$ 2050$ versus US\$1587, respectively, providing a mean difference of $\$ 463(P<0.001)$. Corresponding medical costs were US\$3817 versus US\$3343, providing a mean difference of US\$474 $(P<0.001)$. Although unobserved systematic differences between the 2 medication groups may have existed, as with any retrospective claims database analysis, it was concluded that use of valsartan/HCTZ single-pill combination therapy in hypertension may lead to increased adherence and persistence with a positive financial impact on both prescription and total medical costs. Combination therapy with a CCB plus an ARB also was shown to be a more cost-effective lifetime antihypertensive strategy than monotherapy with either agent alone. ${ }^{78}$

\section{Compliance in the treatment of hypertension}

Hypertension is a common and extremely treatable risk factor for major cardiovascular events and cerebrovascular events. Since together they represent a major cause of morbidity and mortality throughout the developed world, and in many developing nations, one would assume that once a large number of safe and effective medications were developed and widely distributed at reasonable costs, the problem represented by hypertension would gradually diminish to the point of being irrelevant. In fact that has not occurred, and it is useful to examine compliance and its politically correct alternative of adherence.

Any consideration must include an analysis of the problem, its consequences, and suggestive approaches to its resolution or improvement. There is little doubt about the size of the problem of poor compliance with 
antihypertensive therapy. In a recent Italian study, a cohort of 445,356 hypertensive patients aged 40-80 years received their first antihypertensive prescription (monotherapy) during 1999-2002. ${ }^{79}$ Discontinuation was defined by the absence of any antihypertensive therapy during a 90-day period following the end of the last prescription. If during the same period a drug of a different class was added or replaced the original prescription, the treatment modification was considered combination or switching, respectively. The cumulative incidences of discontinuation, combination, and switching were $41 \%, 18 \%$, and $17 \%$ at 1 year and $50 \%$, $25 \%$, and $19 \%$ at 5 years, and inhibitors of the RAAS were associated with the lowest rates of discontinuation. ${ }^{79}$ Drug choice apparently does affect the compliance with treatment options and outcomes in elderly hypertensive patients. ${ }^{80}$ A prospective, single-center study focused on elderly patients and utilized a full range of currently available drugs, which added to its relevance. ${ }^{81}$ The authors found that newer antihypertensive therapies, including ACE inhibitors and ARBs, were associated with greater persistence and better antihypertensive efficacy than older drugs. At the end of the 2-year study, patients who started on diuretics were only half as likely to be still taking their medication compared with the more modern drugs. In addition to the importance of class of antihypertensive therapy, it is critical for physicians to diagnose any cognitive impairment that may exist in the elderly patient, as this may have important implications in terms of treatment compliance. ${ }^{30}$

Because hypertension control rates are unsatisfactory, the role of adherence has been examined. A variety of programs have been suggested including patient motivational factors, social support, and reminding techniques. ${ }^{82}$ For example, a program that included a combination of medical education, regular follow-up by pharmacists, and time-specific medication packs yielded an overall 34\% improvement in medication adherence and significant reductions in SBP of $6.9 \mathrm{mmHg} .{ }^{83}$ Other approaches have included simpler dosing, various drug packaging, and provider interventions including tutorials. In general, although there are some occasional success stories, it is apparent that as yet we have not discovered the "magic bullet" that will ensure appropriate compliance. ${ }^{84}$

\section{The rationale for combination antihypertensive therapy including single-pill combinations}

Control of hypertension is difficult to achieve in clinical practice, especially in high-risk patients, and so-called 'therapeutic inertia' derived from poorly prescribed lifestyle changes, excessive use of monotherapy, and scarce on-treatment modifications may be a significant factor. ${ }^{85}$ The use of combination therapy and, in particular, single-pill combinations, significantly improves BP control without increasing daily pill intake, favoring patient compliance, continuity of treatment, and lower costs to the health care system. ${ }^{2,85-87}$ For example, a recent retrospective analysis of medical and pharmacy claims data found that, compared with free-combination antihypertensive therapy, single-pill combination therapy resulted in $42.5 \%$ greater persistence, $22.1 \%$ greater compliance, $21.3 \%$ fewer hypertension-related hospitalizations, and $20.2 \%$ lower expenditures for hypertension-related services. ${ }^{88}$ Other analyses have similarly demonstrated that subjects taking single-pill combination antihypertensive therapy had significant increases in medication adherence and reductions in resource utilization relative to subjects receiving the same drug classes as separate components. ${ }^{89,90}$ A meta-analysis by Bangalore and colleagues found that single-pill combination therapy reduced the risk of medication nonadherence among hypertensive patients by $24 \%$ compared with free-combination therapy. ${ }^{91}$ Consistent with these findings, current hypertension treatment guidelines recommend single-pill combination therapy in appropriate patients, based on its ability to simplify the treatment schedule and optimize compliance. ${ }^{2}$

\section{Conclusions}

In conclusion, the results indicate that both valsartan/HCTZ and amlodipine/valsartan are excellent options for a broad range of hypertensive patients, including difficult-to-treat populations such as those with severe BP elevations, diabetes (and prediabetes), patients with the cardiometabolic syndrome, and individuals who are obese, elderly, or black. $\mathrm{BP}$ reductions with these combinations are greater than with the different monotherapy components alone, and both combinations are now indicated for first-line use in patients likely to need multiple drugs to achieve their BP goals. Although not discussed here, the clinician also has a number of other ARB-based single-pill combination treatments available (see Table 1) to ensure that a majority of patients with hypertension can attain their BP targets in a timely manner. These ARB-based combinations have the added advantage of good tolerability, with the ARB potentially reducing the adverse metabolic effects of HCTZ and the peripheral edema that may be associated with amlodipine.

Current treatment guidelines recommend first-line combination therapy for patients with stage 2 hypertension 
Table I Angiotensin receptor blocker single-pill combinations

\begin{tabular}{|c|c|}
\hline Combination & Doses available \\
\hline \multicolumn{2}{|l|}{ Diuretic combinations } \\
\hline $\begin{array}{l}\text { Candesartan cilexitil/HCTZ } \\
\left(\text { Atacand-HCT }{ }^{\circledR}\right)^{\mathrm{a}}\end{array}$ & $16 / / 2.5 \mathrm{mg} ; 32 / / 2.5 \mathrm{mg} ; 32 / 25 \mathrm{mg}$ \\
\hline 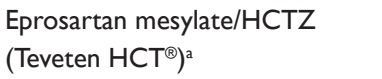 & $600 / 12.5 \mathrm{mg} ; 600 / 25 \mathrm{mg}$ \\
\hline Irbesartan/HCTZ (Avalide ${ }^{\circledR}$ ) & I50//2.5 mg; 300//2.5 mg \\
\hline Losartan/HCTZ (Hyzaar $\left.{ }^{\circledR}\right)$ & $50 / / 2.5 \mathrm{mg} ; 100 / / 2.5 \mathrm{mg} ; 100 / 25 \mathrm{mg}$ \\
\hline $\begin{array}{l}\text { Olmesartan medoxomil/HCTZ } \\
\left(\text { Benicar } \mathrm{HCT}^{\circledR}\right)^{\mathrm{a}}\end{array}$ & $20 / / 2.5 \mathrm{mg} ; 40 / / 2.5 \mathrm{mg} ; 40 / 25 \mathrm{mg}$ \\
\hline 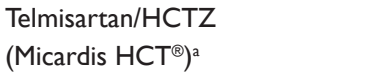 & $40 / / 2.5 \mathrm{mg} ; 80 / / 2.5 \mathrm{mg} ; 80 / 25 \mathrm{mg}$ \\
\hline Valsartan/HCTZ (Diovan-HCT ${ }^{\circledR}$ ) & $\begin{array}{l}\text { I60//2.5 mg; 160/25 mg; } \\
320 / / 2.5 \mathrm{mg} ; 320 / 25 \mathrm{mg}\end{array}$ \\
\hline \multicolumn{2}{|l|}{$\begin{array}{l}\text { Calcium channel blocker } \\
\text { combinations }\end{array}$} \\
\hline Amlodipine/valsartan $\left(\right.$ Exforge $^{\circledR}$ ) & $\begin{array}{l}\text { 5/160 mg; I0//60 mg; 5/320 mg; } \\
10 / 320 \mathrm{mg}\end{array}$ \\
\hline Amlodipine/olmesartan (Azor ${ }^{\circledR}$ ) & $5 / 20 \mathrm{mg} ; 10 / 40 \mathrm{mg}$ \\
\hline
\end{tabular}

${ }^{a}$ The single-pill combination is not approved for first-line use. Abbreviation: HCTZ, hydrochlorothiazide.

(SBP $\geq 160 \mathrm{mmHg}$ and/or DBP $\geq 100 \mathrm{mmHg}$ ) or at high risk for cardiovascular events. ${ }^{2,15} \mathrm{ARB} /$ diuretic or $\mathrm{CCB} /$ ARB combinations would be beneficial for most of these patients. In particular, RAAS inhibitor-based treatments are the preferred option for high-risk hypertensive patients with diabetes, metabolic syndrome, or kidney disease, for example. Some data suggest that black patients, who tend to have more severe hypertension than other racial groups, ${ }^{92}$ may respond less favorably than nonblacks to RAAS inhibitors. ${ }^{93}$ However, the need for combination therapy in a majority of black patients renders any differences in response to monotherapy inconsequential. ${ }^{94,95}$ The increased risk for ACE inhibitor-induced cough and angioedema among black patients ${ }^{94}$ may make ARB-based combinations more attractive.

Whether certain hypertensive populations will benefit more from one particular combination over another depends on several patient-related factors. For example, valsartan/HCTZ (or other $\mathrm{ARB} / \mathrm{HCTZ}$ combinations) may be an adequate option for hypertensive patients without insulin resistance, whereas a $\mathrm{CCB} / \mathrm{RAAS}$ blocker may be a preferred combination for the population with prediabetes, many of whom will need multiple antihypertensive agents. ${ }^{96}$ Diuretics are not preferred first-line treatment in patients with prediabetes or diabetes due to their negative metabolic effects. The findings of ACCOMPLISH, which included 11,506 patients (mean age, 68 years) with hypertension (mean baseline SBP/DBP, 145/80 $\mathrm{mmHg}$ ) and high cardiovascular risk secondary to previous major events or presence of diabetes, suggest that a CCB/RAAS blocker combination may be a better option than a diuretic/RAAS blocker combination for this high-risk population. ${ }^{28}$

In the future, novel RAAS-based combination therapies may become available (eg, dual inhibition of $\mathrm{AT}_{1} / \mathrm{endothelin}$ receptors, $\mathrm{AT}_{1}$ /thromboxane $\mathrm{A}_{2}$ receptors, and $\mathrm{ACE} /$ neutral endopeptidase). ${ }^{97}$ Further simplification of therapy and optimization of adherence may result from the incorporation of three drugs into a single pill. ${ }^{98}$ In addition, the possible benefits of combination antihypertensive therapy in reducing the risk of vascular dementia and cognitive dysfunction will undoubtedly be a focus of upcoming research.

\section{Acknowledgments and disclosures}

The preparation of this manuscript was made possible by funding from Novartis Pharmaceuticals Corporation. Dr Nash and Michael S McNamara (medical writer) drafted the manuscript. Dr Nash reviewed the first draft and revised it critically for important intellectual content. Editorial support for styling of the manuscript and creation of tables and figures was provided by Simon Lancaster. Rita Samuel, Medical Director at Novartis Pharmaceuticals Corporation, USA, checked the scientific accuracy of the data reported from several valsartan studies. Dr Nash received support from Novartis Pharmaceuticals Corporation for the preparation of this manuscript.

\section{References}

1. Fields LE, Burt VL, Cutler JA, Hughes J, Roccella EJ, Sorlie P. The burden of adult hypertension in the United States 1999 to 2000: a rising tide. Hypertension. 2004;44(4):398-404.

2. Mancia G, De Backer G, Dominiczak A, et al. Guidelines for the Management of Arterial Hypertension: The Task Force for the Management of Arterial Hypertension of the European Society of Hypertension (ESH) and of the European Society of Cardiology (ESC). J Hypertens. 2007;25(6):1105-1187.

3. Cushman WC. The burden of uncontrolled hypertension: morbidity and mortality associated with disease progression. J Clin Hypertens (Greenwich). 2003;5(3 Suppl 2):14-22.

4. Papademetriou V. Hypertension and cognitive function. Blood pressure regulation and cognitive function: a review of the literature. Geriatrics. 2005;60(1):20-2, 24.

5. Alcocer L, Cueto L. Hypertension, a health economics perspective. Ther Adv Cardiovasc Dis. 2008;2(3):147-155.

6. Ong KL, Cheung BM, Man YB, Lau CP, Lam KS. Prevalence, awareness, treatment, and control of hypertension among United States adults 1999-2004. Hypertension. 2007;49(1):69-75.

7. Assmann G, Schulte H. The Prospective Cardiovascular Munster (PROCAM) study: prevalence of hyperlipidemia in persons with hypertension and/or diabetes mellitus and the relationship to coronary heart disease. Am Heart J. 1988;116(6 Pt 2):1713-1724. 
8. Wei M, Mitchell BD, Haffner SM, Stern MP. Effects of cigarette smoking, diabetes, high cholesterol, and hypertension on all-cause mortality and cardiovascular disease mortality in Mexican Americans. The San Antonio Heart Study. Am J Epidemiol. 1996;144(11):1058-1065.

9. Kannel WB. Risk stratification in hypertension: new insights from the Framingham Study. Am J Hypertens. 2000;13(1 Pt 2):3S-10S.

10. Thomas F, Rudnichi A, Bacri AM, Bean K, Guize L, Benetos A. Cardiovascular mortality in hypertensive men according to presence of associated risk factors. Hypertension. 2001;37(5):1256-1261.

11. Mancia G, Parati G, Borghi C, et al. Hypertension prevalence, awareness, control and association with metabolic abnormalities in the San Marino population: the SMOOTH study. J Hypertens. 2006;24(5):837-843.

12. Appel LJ, Brands MW, Daniels SR, Karanja N, Elmer PJ, Sacks FM. Dietary approaches to prevent and treat hypertension: a scientific statement from the American Heart Association. Hypertension. 2006;47(2):296-308.

13. Englert HS, Diehl HA, Greenlaw RL, Willich SN, Aldana S. The effect of a community-based coronary risk reduction: the Rockford CHIP. Prev Med. 2007;44(6):513-519.

14. Bavikati VV, Sperling LS, Salmon RD, et al. Effect of comprehensive therapeutic lifestyle changes on prehypertension. Am J Cardiol. 2008;102(12):1677-1680.

15. Chobanian AV, Bakris GL, Black HR, et al. The Seventh Report of the Joint National Committee on Prevention, Detection, Evaluation, and Treatment of High Blood Pressure: the JNC 7 report. JAMA. 2003;289(19):2560-2572.

16. Dahlöf B, Sever PS, Poulter NR, et al. Prevention of cardiovascular events with an antihypertensive regimen of amlodipine adding perindopril as required versus atenolol adding bendroflumethiazide as required, in the Anglo-Scandinavian Cardiac Outcomes Trial-Blood Pressure Lowering Arm (ASCOT-BPLA): a multicentre randomised controlled trial. Lancet. 2005;366(9489):895-906.

17. Bakris GL, Toto RD, McCullough PA, Rocha R, Purkayastha D, Davis P. Effects of different ACE inhibitor combinations on albuminuria: results of the GUARD study. Kidney Int. 2008;73(11):1303-1309.

18. Effects of treatment on morbidity in hypertension. Results in patients with diastolic blood pressures averaging 115 through $129 \mathrm{mmHg}$. JAMA. 1967;202(11):1028-1034

19. Effects of treatment on morbidity in hypertension. II. Results in patients with diastolic blood pressure averaging 90 through $114 \mathrm{~mm} \mathrm{Hg.} \mathrm{JAMA.}$ 1970;213(7):1143-1152.

20. Five-year findings of the hypertension detection and follow-up program. I. Reduction in mortality of persons with high blood pressure, including mild hypertension. Hypertension Detection and Follow-up Program Cooperative Group. JAMA. 1979;242(23):2562-2571.

21. Prevention of stroke by antihypertensive drug treatment in older persons with isolated systolic hypertension. Final results of the Systolic Hypertension in the Elderly Program (SHEP). SHEP Cooperative Research Group. JAMA. 1991;265(24):3255-3264.

22. Staessen JA, Fagard R, Thijs L, et al. Randomised double-blind comparison of placebo and active treatment for older patients with isolated systolic hypertension. The Systolic Hypertension in Europe (Syst-Eur) Trial Investigators. Lancet. 1997;350(9080):757-764.

23. Black HR, Elliott WJ, Grandits G, et al. Principal results of the Controlled Onset Verapamil Investigation of Cardiovascular End Points (CONVINCE) trial. JAMA. 2003;289(16):2073-2082.

24. Pepine CJ, Handberg EM, Cooper-DeHoff RM, et al. A calcium antagonist vs a non-calcium antagonist hypertension treatment strategy for patients with coronary artery disease. The International VerapamilTrandolapril Study (INVEST): a randomized controlled trial. JAMA. 2003;290(21):2805-2816.

25. Lithell H, Hansson L, Skoog I, et al. The Study on Cognition and Prognosis in the Elderly (SCOPE): principal results of a randomized double-blind intervention trial. J Hypertens. 2003;21(5):875-886.

26. Nissen SE, Tuzcu EM, Libby P, et al. Effect of antihypertensive agents on cardiovascular events in patients with coronary disease and normal blood pressure: the CAMELOT study: a randomized controlled trial. JAMA. 2004;292(18):2217-2225.
27. Julius S, Kjeldsen SE, Weber M, et al. Outcomes in hypertensive patients at high cardiovascular risk treated with regimens based on valsartan or amlodipine: the VALUE randomised trial. Lancet. 2004;363(9426):2022-2031.

28. Jamerson K, Weber MA, Bakris GL, et al. Benazepril plus amlodipine or hydrochlorothiazide for hypertension in high-risk patients. $N$ Engl J Med. 2008;359(23):2417-2428.

29. Duron E, Rigaud AS, Dubail D, et al. Effects of antihypertensive therapy on cognitive decline in Alzheimer's disease. Am J Hypertens. 2009;22(9):1020-1024.

30. Skoog I. Antihypertensive treatment and dementia prevention. Lancet Neurol. 2008;7(8):664-665.

31. Peters R, Beckett N, Forette F, et al. Incident dementia and blood pressure lowering in the Hypertension in the Very Elderly Trial cognitive function assessment (HYVET-COG): a double-blind, placebo controlled trial. Lancet Neurol. 2008;7(8):683-689.

32. Atlas SA. The renin-angiotensin aldosterone system: pathophysiological role and pharmacologic inhibition. J Manag Care Pharm. 2007; 13(8 Suppl S-b):S9-S20.

33. Weir MR. Providing end-organ protection with renin-angiotensin system inhibition: the evidence so far. J Clin Hypertens (Greenwich). 2006;8(2):99-105.

34. Matchar DB, McCrory DC, Orlando LA, et al. Systematic review: comparative effectiveness of angiotensin-converting enzyme inhibitors and angiotensin II receptor blockers for treating essential hypertension. Ann Intern Med. 2008;148(1):16-29.

35. Maggioni AP, Fabbri G. VALIANT (VALsartan In Acute myocardial iNfarcTion) trial. Expert Opin Pharmacother. 2005;6(3):507-512.

36. Turnbull F, Neal B, Pfeffer M, et al. Blood pressure-dependent and independent effects of agents that inhibit the renin-angiotensin system. J Hypertens. 2007;25(5):951-958.

37. Reboldi G, Angeli F, Cavallini C, Gentile G, Mancia G, Verdecchia P. Comparison between angiotensin-converting enzyme inhibitors and angiotensin receptor blockers on the risk of myocardial infarction, stroke and death: a meta-analysis. J Hypertens. 2008;26(7):1282-1289.

38. Yusuf S, Teo KK, Pogue J, et al. Telmisartan, ramipril, or both in patients at high risk for vascular events. $N$ Engl J Med. 2008;358(15): 1547-1559.

39. Mann JF, Schmieder RE, McQueen M, et al. Renal outcomes with telmisartan, ramipril, or both, in people at high vascular risk (the ONTARGET study): a multicentre, randomised, double-blind, controlled trial. Lancet. 2008;372(9638):547-553.

40. Brown MJ, Cruickshank JK, Dominiczak AF, et al. Better blood pressure control: how to combine drugs. J Hum Hypertens. 2003;17(2):81-86.

41. Cohn JN, Tognoni G. A randomized trial of the angiotensinreceptor blocker valsartan in chronic heart failure. $N$ Engl $J$ Med. 2001;345(23):1667-1675.

42. Pfeffer MA, McMurray JJ, Velazquez EJ, et al. Valsartan, captopril, or both in myocardial infarction complicated by heart failure, left ventricular dysfunction, or both. N Engl J Med. 2003;349(20):1893-1906.

43. Benz JR, Black HR, Graff A, Reed A, Fitzsimmons S, Shi Y. Valsartan and hydrochlorothiazide in patients with essential hypertension. A multiple dose, double-blind, placebo controlled trial comparing combination therapy with monotherapy. J Hum Hypertens. 1998;12(12): 861-866.

44. Pool JL, Glazer R, Weinberger M, Alvarado R, Huang J, Graff A. Comparison of valsartan/hydrochlorothiazide combination therapy at doses up to $320 / 25 \mathrm{mg}$ versus monotherapy: a double-blind, placebocontrolled study followed by long-term combination therapy in hypertensive adults. Clin Ther. 2007;29(1):61-73.

45. Jamerson KA, Zappe DH, Collins L, Daley WL. The time to blood pressure (BP) control by initiating antihypertensive therapy with a higher dose of valsartan $(160 \mathrm{mg})$ or valsartan/hydrochlorothiazide compared to low-dose valsartan $(80 \mathrm{mg})$ in the treatment of hypertension. The VELOCITY study. Presented at the 22nd Annual Scientific Meeting of the American Society of Hypertension, May 19-22, 2007, Chicago, IL, USA. 
46. Kolloch RE, Ferber P. A randomized, double-blind study to compare a valsartan-based versus an amlodipine-based treatment algorithm in achieving blood pressure control: The PROMPT study. Presented at Hypertension 2008, the Joint Congress of the 18th Scientific Meeting of the European Society of Hypertension and the 22nd Scientific Meeting of the International Society of Hypertension, June 14-19, 2008, Berlin, Germany.

47. Lacourcière Y, Wright Jr JT, Samuel R, Zappe D, Purkayastha D, Black HR. Effects of force-titrated valsartan/hydrochlorothiazide versus amlodipine/hydrochlorothiazide on ambulatory blood pressure in patients with stage 2 hypertension: the EVALUATE study. Blood Press Monit. 2009;14(3):112-120.

48. Meier P, Maillard M, Burnier M. The future of angiotensin II inhibition in cardiovascular medicine. Curr Drug Targets Cardiovasc Haematol Disord. 2005;5(1):15-30.

49. Calhoun DA, Glazer RD, Pettyjohn FS, Coenen PD, Zhao Y, Grosso A. Efficacy and tolerability of combination therapy with valsar$\tan$ /hydrochlorothiazide in the initial treatment of severe hypertension. Curr Med Res Opin. 2008;24(8):2303-2311.

50. Zappe DH, Sowers JR, Hsueh WA, et al. Metabolic and antihypertensive effects of combined angiotensin receptor blocker and diuretic therapy in prediabetic hypertensive patients with the cardiometabolic syndrome. J Clin Hypertens (Greenwich). 2008;10(12):894-903.

51. Raij L, Sowers JR, Jialal I, et al. Metabolic effects of combination angiotensin receptor blockade/hydrochlorothiazide in pre-diabetic, obese, hypertensive patients. Presented at the 18th Scientific Meeting of the European Society of Hypertension and the 22nd Scientific Meeting of the International Society of Hypertension, June 14-19, 2008, Berlin, Germany.

52. White WB, Calhoun DA, Samuel R, Taylor AA, Zappe DH, Purkayastha D. Improving blood pressure control: increase the dose of diuretic or switch to a fixed-dose angiotensin receptor blocker/diuretic? The valsartan hydrochlorothiazide diuretic for initial control and titration to achieve optimal therapeutic effect (Val-DICTATE) trial. J Clin Hypertens (Greenwich). 2008;10(6):450-458.

53. Mallion JM, Carretta R, Trenkwalder P, et al. Valsartan/hydrochlorothiazide is effective in hypertensive patients inadequately controlled by valsartan monotherapy. Blood Press Suppl. 2003;12(Suppl 1):36-43.

54. Malacco E, Santonastaso M, Vari NA, et al. Comparison of valsartan $160 \mathrm{mg}$ with lisinopril $20 \mathrm{mg}$, given as monotherapy or in combination with a diuretic, for the treatment of hypertension: the Blood Pressure Reduction and Tolerability of Valsartan in Comparison with Lisinopril (PREVAIL) study. Clin Ther. 2004;26(6):855-865.

55. Fuenfstueck R, Hempel RD, Ansari A, Weidinger G, Klebs S. Efficacy and safety of combination therapy using high- or low-dose hydrochlorothiazide with valsartan or other Angiotensin-receptor blockers. $A d v$ Ther. 2005;22(3):263-277.

56. Fogari R, Zoppi A, Mugellini A, et al. Hydrochlorothiazide added to valsartan is more effective than when added to olmesartan in reducing blood pressure in moderately hypertensive patients inadequately controlled by monotherapy. Adv Ther. 2006;23(5):680-695.

57. Schweizer J, Hilsmann U, Neumann G, Handrock R, Klebs S. Efficacy and safety of valsartan 160/HCTZ $25 \mathrm{mg}$ in fixed combination in hypertensive patients not controlled by candesartan $32 \mathrm{mg}$ plus HCTZ $25 \mathrm{mg}$ in free combination. Curr Med Res Opin. 2007;23(11):2877-2885.

58. Everett BM, Glynn RJ, Danielson E, Ridker PM. Combination therapy versus monotherapy as initial treatment for stage 2 hypertension: A prespecified subgroup analysis of a community-based, randomized, open-label trial. Clin Ther. 2008;30(4):661-672.

59. Weir MR, Levy D, Crikelair N, Rocha R, Meng X, Glazer R. Time to achieve blood-pressure goal: influence of dose of valsartan monotherapy and valsartan and hydrochlorothiazide combination therapy. Am J Hypertens. 2007;20(7):807-815.

60. Philipp T, Smith TR, Glazer R, et al. Two multicenter, 8-week, randomized, double-blind, placebo-controlled, parallel-group studies evaluating the efficacy and tolerability of amlodipine and valsartan in combination and as monotherapy in adult patients with mild to moderate essential hypertension. Clin Ther. 2007;29(4):563-580.
61. Smith TR, Philipp T, Vaisse B, et al. Amlodipine and valsartan combined and as monotherapy in stage 2, elderly, and black hypertensive patients: subgroup analyses of 2 randomized, placebo-controlled studies. J Clin Hypertens (Greenwich). 2007;9(5):355-364.

62. Destro M, Luckow A, Samson M, Kandra A, Brunel P. Efficacy and safety of amlodipine/valsartan compared with amlodipine monotherapy in patients with stage 2 hypertension: a randomized, double-blind, multicenter study: the EX-EFFeCTS Study. J Am Soc Hypertens. 2008;2(4):294-302.

63. Poldermans D, Glazes R, Kargiannis S, et al. Tolerability and blood pressure-lowering efficacy of the combination of amlodipine plus valsartan compared with lisinopril plus hydrochlorothiazide in adult patients with stage 2 hypertension. Clin Ther. 2007;29(2):279-289.

64. Flack JM, Calhoun DA, Satlin L, Barbier M, Hilkert R, Brunel P. Efficacy and safety of initial combination therapy with amlodipine/ valsartan compared with amlodipine monotherapy in black patients with stage 2 hypertension: the EX-STAND study. J Hum Hypertens. 2009;23(7):479-489.

65. Allemann Y, Fraile B, Lambert M, Barbier M, Ferber P, Izzo JL Jr. Efficacy of the combination of amlodipine and valsartan in patients with hypertension uncontrolled with previous monotherapy: the Exforge in Failure after Single Therapy (EX-FAST) study. J Clin Hypertens (Greenwich). 2008;10(3):185-194.

66. Sinkiewicz W, Glazer RD, Kavoliuniene A, et al. Efficacy and tolerability of amlodipine/valsartan combination therapy in hypertensive patients not adequately controlled on valsartan monotherapy. Curr Med Res Opin. 2009;25(2):315-324.

67. Brachmann J, Ansari A, Mahla G, Handrock R, Klebs S. Effective and safe reduction of blood pressure with the combination of amlodipine $5 \mathrm{mg}$ and valsartan $160 \mathrm{mg}$ in hypertensive patients not controlled by calcium channel blocker monotherapy. Adv Ther. 2008;25(5):399-411.

68. Fogari R, Zoppi A, Mugellini A, et al. Efficacy and safety of two treatment combinations of hypertension in very elderly patients. Arch Gerontol Geriatr. 2009;48(3):401-405.

69. Trenkwalder P, Schaetzl R, Borbas E, Handrock R, Klebs S. Combination of amlodipine $10 \mathrm{mg}$ and valsartan $160 \mathrm{mg}$ lowers blood pressure in patients with hypertension not controlled by an ACE inhibitor/CCB combination. Blood Press. 2008;17(4):13-21.

70. Weycker D, Keskinaslan A, Levy DG, Edelsberg J, Kartashov A, Oster G. Effectiveness of add-on therapy with amlodipine in hypertensive patients receiving valsartan. Blood Press. 2008;17(Suppl 2):5-12.

71. Braun N, Ulmer HJ, Ansari A, Handrock R, Klebs S. Efficacy and safety of the single pill combination of amlodipine $10 \mathrm{mg}$ plus valsartan $160 \mathrm{mg}$ in hypertensive patients not controlled by amlodipine $10 \mathrm{mg}$ plus olmesartan $20 \mathrm{mg}$ in free combination. Curr Med Res Opin. 2009;25(2):421-430.

72. Philipp T, Glazer RD, Zhao Y, Pospiech R. Long-term tolerability and efficacy of the combination of amlodipine/valsartan in hypertensive patients: a 54-week, open-label extension study. Curr Med Res Opin. 2009;25(1):187-193.

73. Messerli FH. Vasodilatory edema: a common side effect of antihypertensive therapy. Am J Hypertens. 2001;14(9 Pt 1):978-979.

74. Schrader J, Salvetti A, Calvo C, et al. The combination of amlodipine/ valsartan 5/160 $\mathrm{mg}$ produces less peripheral oedema than amlodipine $10 \mathrm{mg}$ in hypertensive patients not adequately controlled with amlodipine $5 \mathrm{mg}$. Int J Clin Pract. 2009;63(2):217-225.

75. Bramley TJ, Gerbino PP, Nightengale BS, Frech-Tamas F. Relationship of blood pressure control to adherence with antihypertensive monotherapy in 13 managed care organizations. JManag Care Pharm. 2006;12(3):239-245.

76. Jackson II KC, Sheng X, Nelson RE, Keskinaslan A, Brixner DI. Adherence with multiple-combination antihypertensive pharmacotherapies in a US managed care database. Clin Ther. 2008;30(8):1558-1563.

77. Brixner DI, Jackson KC, Sheng X, Nelson RE, Keskinaslan A. Assessment of adherence, persistence, and costs among valsartan and hydrochlorothiazide retrospective cohorts in free-and fixed-dose combinations. Curr Med Res Opin. 2008;24(9):2597-2607. 
78. Saito I, Kobayashi M, Matsushita Y, Mori A, Kawasugi K, Saruta T. Cost-utility analysis of antihypertensive combination therapy in Japan by a Monte Carlo simulation model. Hypertens Res. 2008;31(7): 1373-1383.

79. Corrao G, Zambon A, Parodi A, et al. Discontinuation of and changes in drug therapy for hypertension among newly-treated patients: a population-based study in Italy. J Hypertens. 2008;26(4):819-824.

80. Weber MA, Wenger NK. Drug choice affects treatment compliance and blood pressure outcomes in elderly hypertensive patients. Am J Geriatr Cardiol. 2007;16(5):277-278.

81. Borghi C, Veronesi M, Dormi A, Prandin MG, Cosentino E, Strocchi E. Persistence of treatment and blood pressure control in elderly hypertensive patients treated with different classes of antihypertensive drugs. Am J Geriatr Cardiol. 2007;16(5):280-286.

82. Kravitz RL, Melnikow J. Medical adherence research: time for a change in direction? Med Care. 2004;42(3):197-199.

83. Lee JK, Grace KA, Taylor AJ. Effect of a pharmacy care program on medication adherence and persistence, blood pressure, and low-density lipoprotein cholesterol: a randomized controlled trial. JAMA. 2006;296(21):2563-2571.

84. Krousel-Wood M, Hyre A, Muntner P, Morisky D. Methods to improve medication adherence in patients with hypertension: current status and future directions. Curr Opin Cardiol. 2005;20(4):296-300.

85. Ferri C, Croce G, Desideri G. Role of combination therapy in the treatment of hypertension: Focus on valsartan plus amlodipine. Adv Ther. 2008;25(4):299-319.

86. Taylor AA. Combination drug treatment of hypertension: have we come full circle? Curr Cardiol Rep. 2004;6(6):421-426.

87. Faulkner MA, Hilleman DE. Amlodipine/benazepril: fixed dose combination therapy for hypertension. Expert Opin Pharmacother. 2001;2(1):165-178.

88. Hess G, Hill J, Lau H, Dastani H, Chaudhari P. Medication utilization patterns and hypertension-related expenditures among patients who were switched from fixed-dose to free-combination antihypertensive therapy. $P \& T$. 2008;33(11):652-666.
89. Gerbino PP, Shoheiber O. Adherence patterns among patients treated with fixed-dose combination versus separate antihypertensive agents. Am J Health Syst Pharm. 2007;64(12):1279-1283.

90. Taylor AA, Shoheiber O. Adherence to antihypertensive therapy with fixed-dose amlodipine besylate/benazepril $\mathrm{HCl}$ versus comparable component-based therapy. Congest Heart Fail. 2003;9(6):324-332.

91. Bangalore S, Kamalakkannan G, Parkar S, Messerli FH. Fixed-dose combinations improve medication compliance: a meta-analysis. Am J Med. 2007;120(8):713-719.

92. Gadegbeku CA, Lea JP, Jamerson KA. Update on disparities in the pathophysiology and management of hypertension: focus on African Americans. Med Clin North Am. 2005;89(5):921-33, 930.

93. Park IU, Taylor AL. Race and ethnicity in trials of antihypertensive therapy to prevent cardiovascular outcomes: a systematic review. Ann Fam Med. 2007;5(5):444-452.

94. Douglas JG, Bakris GL, Epstein M, et al. Management of high blood pressure in African Americans: consensus statement of the Hypertension in African Americans Working Group of the International Society on Hypertension in Blacks. Arch Intern Med. 2003;163(5):525-541.

95. Flack JM. Epidemiology and unmet need in hypertension. J Manag Care Pharm. 2007;13(8 Suppl S-b):S2-S8.

96. Garber AJ, Handelsman Y, Einhorn D, et al. Diagnosis and management of prediabetes in the continuum of hyperglycemia: when do the risks of diabetes begin? A consensus statement from the American College of Endocrinology and the American Association of Clinical Endocrinologists. Endocr Pract. 2008;14(7):933-946.

97. Aulakh GK, Sodhi RK, Singh M. An update on non-peptide angiotensin receptor antagonists and related RAAS modulators. Life Sci. 2007;81(8):615-639.

98. Elijovich F, Laffer C. A role for single-pill triple therapy in hypertension. Ther Adv Cardiovasc Dis. 2009;3(3):231-240.
Integrated Blood Pressure Control

\section{Publish your work in this journal}

Integrated Blood Pressure Control is an international, peer-reviewed open-access journal focusing on the integrated approach to managing hypertension and risk reduction. Treating the patient and comorbidities together with diet and lifestyle modification and optimizing healthcare resources through a multidisciplinary team approach constitute key

\section{Dovepress}

features of the journal. This journal is indexed on American Chemical Society's Chemical Abstracts Service (CAS). The manuscript management system is completely online and includes a very quick and fair peerreview system, which is all easy to use. Visit http://www.dovepress.com/ testimonials.php to read real quotes from published authors. 